(C2020. This manuscript version is made available under the CC-BY-NC-ND 4.0 license http://creativecommons.org/ licenses/by-nc-nd/4.0/

\title{
Tetrahedron
}

\section{Short axially asymmetrically 1, 3-disubstituted pyrene-based color-tunable emitters: Synthesis, characterization and optical properties --Manuscript Draft--}

\begin{tabular}{|c|c|}
\hline Manuscript Number: & TET-D-20-00998R1 \\
\hline Article Type: & Full Length Article \\
\hline Keywords: & $\begin{array}{l}\text { pyrene; asymmetric synthesis; Photo-physical properties; Intramolecular charge } \\
\text { transfer; density functional theory }\end{array}$ \\
\hline Corresponding Author: & $\begin{array}{l}\text { Takehiko Yamato, Ph.D. } \\
\text { Saga University } \\
\text { Saga, JAPAN }\end{array}$ \\
\hline First Author: & Chuan-Zeng Wang, PhD \\
\hline \multirow[t]{8}{*}{ Order of Authors: } & Chuan-Zeng Wang, PhD \\
\hline & Zi-Jin Pang \\
\hline & Ze-Dong Yu \\
\hline & Wen-Xuan Zhao \\
\hline & Zhao-Xuan Zeng \\
\hline & Zi-Yan Zhou, PhD \\
\hline & Carl Redshaw, PhD \\
\hline & Takehiko Yamato, Ph.D. \\
\hline Abstract: & $\begin{array}{l}\text { In contrast to conventional pyrene-based emitters which feature D-m-A type structures, } \\
\text { a new class of emitters possessing a short axis are gaining constant interest owing to } \\
\text { both their academic importance and promising applications in organic optoelectronic } \\
\text { materials. Herein, donor and acceptor substituents were introduced at 1-, 3-positions } \\
\text { by employing a two step of bromination reaction which enabled first } \\
\text { prepared according to the non-statistic. Two 1-donor-3-acceptor pyrenes were } \\
\text { systematically investigated by } 1 \mathrm{H} / 13 \mathrm{C} \text { NMR spectroscopy, optical spectroscopy, as } \\
\text { well as by theoretical calculations. The preliminary research of the substituent positions } \\
\text { and substitutions pattern on the properties of the materials as well as on the frontier } \\
\text { orbitals is reported. And the experimental results indicated that the strong impact on } \\
\text { the photophysical properties endowed with the possibility of precise color-control of } \\
\text { pyrene derivatives through substituent variation. }\end{array}$ \\
\hline
\end{tabular}


Dear Editor,

We are submitting the manuscript entitled "Short axially asymmetrically 1, 3-disubstituted pyrene-based color-tunable emitters: Synthesis, characterization and optical properties" for consideration as a full paper in Tetrahedron.

The manuscript is submitted to Tetrahedron because:

In this manuscript, we present two highly fluorescent and stable D- $\pi$-A emitters, which were synthesized by employing two bromination steps which enabled the non-statistical to be accessed. We have studies these two short axially asymmetrically 1, 3-disubstituted pyrene-based color-tunable emitters by UV-vis absorption spectroscopy and fluorescence emission spectroscopy in solution. We have researched the influence of the positions and pattern of the substituents on the properties of the products as well as on the frontier orbitals. This research shows that the strategy is not only useful in the design of novel chromophores but could also enable the preparation of high-efficiency opto-electronic materials.

This article has not been published elsewhere in whole or in part. All authors have read and approved the content, and agree to submit for consideration for publication in the journal. There are no any ethical/legal conflicts involved in the article.

Your consideration of this manuscript is highly appreciated, and hopefully our paper is a worthwhile addition to your journal.

Yours faithfully,

Prof. Dr. Takehiko Yamato (corresponding author)

Department of Applied Chemistry

Faculty of Science and Engineering

Saga University

Honjo-machi 1, Saga-shi, Saga 840-8502, Japan

Fax: (internet.) + 81(0)952/28-8548

E-mail: yamatot@cc.saga-u.ac.jp 
Ms. Ref. No.: TET-D-20-00998

Title: Short axially asymmetrically 1, 3-disubstituted pyrene-based color-tunable emitters: Synthesis, characterization and optical properties

Journal: Tetrahedron

Correspondence Author: Prof. Dr. Takehiko Yamato

We have addressed the points as requested, detailed in blue below.

Reviewers' comments:

$* * * * * * * * * * * * * * * * * *$

Reviewer \#1: The manuscript by Zhou and Yamato presents two new pyrene derivatives bearing donors/acceptors at the 1- and 3-positions. Hence, this is a study of pyrenes with a charge transfer transition along the short axis of the pyrene core. The compounds were nicely synthesized, fully characterized and their properties investigated. However, there are a couple of things that are unclear:

--It would be nice if the authors can explain why they chose their specific substituents.

- Why did the authors decide to add an ethynyl spacer? It is hard to understand the observed properties in this study because the authors compare their results only with their previously reported compound 7. However, they changed two factors at the same time. On the one hand, an ethynyl spacer was added on one site and, on the other hand, donors and acceptors have been added on the para position of the phenyl ring. A comparison to a derivative without an ethynyl spacer would be great to see the actual influence of the donors and acceptors on these positions.

Response: Thank you very much for your advices. Actually, we have also reported many pyrene derivatives with ethynyl spacer in our previous work, so we chose those specific substituents to present the significance of our current strategy. However, as reviewer said, it is unconvincing just choosing compound 7, so we have added further descriptions in the revised manuscript.

- A comparison with other D/A-pyrenes which have such donor/acceptor groups at other positions is missing. As such, it is not really an intensive research study of the substituent positions or substitution pattern as the authors state in their abstract.

Response: In our manuscript, we focus on two works: synthetic strategy and structure-property relationship. Based on the novel strategy, we've studied the effect substituent positions or substitution pattern to some extent. So according 
to referee's suggestion, we have improved the statement in abstract.

- For compound $6 \mathrm{a}$, the TOC picture and the idea of charge transfer nature along the short axis of the molecule does not really fit. According to the DFT calculations, the charge transfer is rather from the donor substituent to the pyrene core as there is no acceptor at the 1,3 positions. Thus, the authors do not present two 1-donor-3-acceptor pyrenes, but one such compound, so they should rewrite that. The authors should also be aware that for CT cases, the CAMB3LYP functional is typically a better one to use than B3LYP.

Response: Thank you very much for your suggestion. We have improved the TOC graph in the revised manuscript. In this system, we provide a useful strategy to access asymmetrically 1, 3-disubstituted pyrene-based emitters, moreover, based on this strategy, we can construct D- $\pi$-A /ICT systems easily. For these two compounds, according to the DFT results, we can found that the 4- $N, N$-dimethylaminophenyl moiety is donor, and the other substituent, especially for 4-formylphenyl, is acceptor. Ongoing works are focusing on this type of emitters with typical donor and acceptor groups and will be published soon.

-Abstract line 28-30: Seems like there is a word missing or so.

Response: Thank you very much for your advices, but we did not find the missing word. We would appreciate if you could improve it possible.

Page 1, left column, line 55: the word "consists" is too much here and citations are missing for the statement here.

Response: According to referee's suggestion, we have improved this part in the revised manuscript.

Page 2, synthesis and discussion part: It is somehow confusing to number compound 7-tert-butyl-1,3-dibromopyrene when it is not on any scheme or figure. The number is not necessary so I would suggest removing it or adding it (and cpd 7) to a Figure/Scheme.

Response: We did not add the structure in the text as scheme or figure, but we described it in Figure S1 in the Supporting Information file.

Page 2, right column, first sentence: "...However, the sensitivity to experimental leads to the formation of complex by-products" there is a word missing (maybe 'conditions'?) 
Response: Thank you very much for your careful review, we have added the word "conditions" in the revised text.

Page 3, left column, line 3: It is not possible to judge whether the absorption bands are strong when you did not measure the extinction coefficients.

Response: Thank you very much for your professional and constructive suggestion, we have improved the description in the revised manuscript.

Page 3, left column, line 11-17: Why are the low energy absorptions more intense, compared to the pi-pi* transitions at higher energies, when they possess CT-nature? Why is the lowest energy absorption of compound 6a nearly as far bathochromically shifted as that of $6 \mathrm{~b}$ ? In $6 \mathrm{a}$ there is not really a charge transfer from the substituent at the 3 position to the 1 position. Your calculations show that the acceptor is rather the pyrene core itself. Thus, the differences observed here to compound 7 rather seem to come from the additional ethynyl spacer.

Response: Thank you very much for your professional and constructive suggestion, we have improved this part in the revised manuscript.

Page 3, left column, line 15-16: "charge transfer from the aryl group to the arylethynyl units via the pyrene core" this is confusing, it should be the other way around as the substituent with the ethynyl unit is the donor.

Response: Thank you very much for your advices, there is a mistake, we have revised it in the text.

Page 3, left column, line 39: add the word "yields" after "photoluminescence quantum".

Response: Thank you very much for your suggestion, we have added the word "yields" in the revised manuscript.

Page 3, left column, line 43-44: Do the authors have an explanation for the increased quantum yield compared to compound 7 ?

Response: According to referee's advices, we have added an explanation in the revised manuscript.

Page 3, left column, line 60: remove either the word "two" or "both" in the last sentence and the new sentence starting there.

Response: Thank you very much for your suggestion, we have removed the word "two" in the revised manuscript.

Page 3, Figure 1: The PL is normalized, so please add this information to the right y-axis title. 
Response: According to referee's advices, we have added necessary information in the revised manuscript.

Page 3, right column, line 47: Why is the slope value for compound 6a larger than for compound $6 \mathrm{~b}$ ? As compound $6 \mathrm{~b}$ should have a larger CT character, it should be the other way around.

Response: As the referee said, the slope value for compound 6a is larger than for compound $6 \mathrm{~b}$ in theory, and the unconventional experimental results are also little confusing. Maybe there is an effect when we fit the linear correlation of Lippert-Mataga by software.

Page 4, left column, line 29: Compound 6a does not have a formyl acceptor. Please rewrite this sentence.

Response: Thank you very much for your careful review, we have rewritten this sentence in the revised manuscript.

Page 4, left column, line 33: what trend of the emitters is meant? Since there are only two compounds, the authors can not talk about a "trend" furthermore it is not clear what they mean here.

Response: According to referee's advices, we have improved this part in the revised manuscript.

Page 4-5, where is the experimental part for compound 6a? Since compound 5a comes up twice, I guess there is a typo and it should be the one under 4.7. The $\mathrm{CHCl} 3$ signal looks odd. The integrals from the SI do not fit with what is written in the experimental part. At $8.17 \mathrm{ppm}$ there is no triplet recognizable. The authors should fix this NMR.

Page 5, point 4.8: $1 \mathrm{H}-\mathrm{NMR}$ of $6 \mathrm{~b}$ : According to the NMR from the SI, it looks like the authors forgot to calibrate the signals to $\mathrm{CDCl} 3$ as its not at $7.26 \mathrm{ppm}$. So are the reported chemical shifts right?

Response: Thank you very much for your careful review, there is a mistake for compound 6a, we have improved it. And we also improved the 1H-NMR spectra of $6 \mathrm{~b}$ (Figure S9) in supporting information and revised the NMR data in the experimental part in text.

SI: Figure S16: Why does compound 6b have a shoulder (in the higher energy region) in DMF? This shoulder is not there in the other solvents.

Response: In polar solvent, the weak electronic interactions between adjacent molecules present some influence, it could lead to form multi emission in the higher energy region and in the lower energy region.

Hopefully we have addressed the reviewer's concerns. 


\section{Graphical Abstract}

3

4

5

7

\section{Short axially asymmetrically 1, 3-disubstituted pyrene-based color-tunable emitters: Synthesis, characterization and optical properties}

Chuan-Zeng Wang ${ }^{a, b}$, Zi-Jin Pang $^{a}$, Ze-Dong Yu ${ }^{a}$, Zhao-Xuan Zeng ${ }^{a}$, Wen-Xuan Zhao ${ }^{a}$, Zi-Yan Zhou ${ }^{a} *$, Carl Redshaw $^{c}$, Takehiko Yamato ${ }^{b, *}$

School of Chemical Engineering, Shandong University of Technology, Zibo 255049, P. R. China,

E-mail:zyzhou@sdut.edu.cn

8 Department of Applied Chemistry, Faculty of Science and Engineering, Saga University, Honjo-machi 1, Saga, 19 840-8502 Japan, E-mail: yamatot@cc.saga-u.ac.jp

$2 \Theta$ Department of Chemistry, The University of Hull, Cottingham Road, Hull, Yorkshire, HU6 7RX, UK

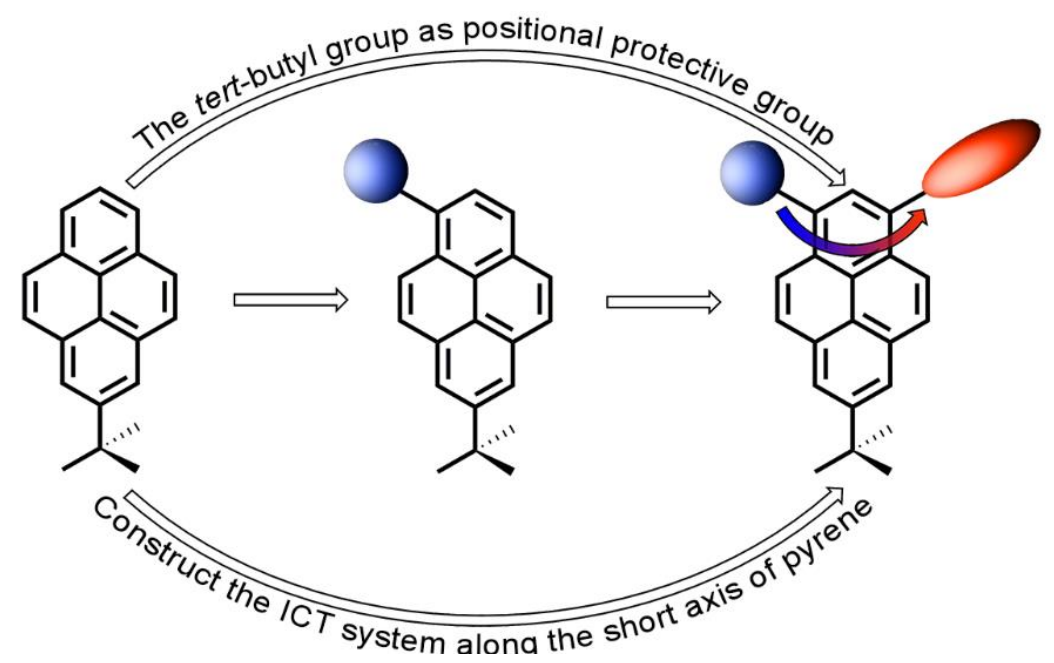




\title{
Short axially asymmetrically 1, 3-disubstituted pyrene-based color-tunable emitters: Synthesis, characterization and optical properties
}

\author{
Chuan-Zeng Wang ${ }^{a, b}$, Zi-Jin Pang ${ }^{a}$, Ze-Dong Yu ${ }^{a}$, Zhao-Xuan Zeng ${ }^{a}$, Wen-Xuan Zhao ${ }^{a}$, Zi-Yan Zhou, ${ }^{a}$ \\ Carl Redshaw ${ }^{c}$, Takehiko Yamato ${ }^{b, *}$ \\ ${ }^{a}$ School of Chemical Engineering, Shandong University of Technology, Zibo 255049, P. R. China, E-mail: zyzhou@sdut.edu.cn \\ ${ }^{b}$ Department of Applied Chemistry, Faculty of Science and Engineering, Saga University, Honjo-machi 1, Saga, 840-8502 Japan, E-mail: \\ yamatot@cc.saga-u.ac.jp \\ Department of Chemistry, The University of Hull, Cottingham Road, Hull, Yorkshire, HU6 7RX, UK
}

\section{ARTICLE INFO}

ABSTRACT

Article history:

Received

Received in revised form

Accepted

Available online

Keywords:

Pyrene chemistry

Asymmetric synthesis

Color-tunable emitters

Photo-physical properties

Density Functional Theory

In contrast to conventional pyrene-based emitters which feature $\mathrm{D}-\pi$-A type structures, a new class of emitters possessing a short axis are gaining constant interest owing to both their academic importance and promising applications in organic optoelectronic materials. Herein, donor and acceptor substituents were introduced at 1-, 3-positions by employing a two step of bromination reaction which enabled first prepared according to the non-statistic. Two 1donor-3-acceptor pyrenes were systematically investigated by ${ }^{1} \mathrm{H} /{ }^{13} \mathrm{C}$ NMR spectroscopy, optical spectroscopy, and theoretical calculations. The preliminary research of the substituent positions and substitutions pattern on the properties of the materials as well as on the frontier orbitals is reported. And the experimental results indicated that the strong impact on the photophysical properties endowed with the possibility of precise color-control of pyrene derivatives through substituent variation.

2019 Elsevier Ltd. All rights reserved.

\section{Introduction}

In recent years, the functionalization of pyrene has inspired numerous researchers due to its unique properties in the material arena. ${ }^{1-3}$ The synthesis of asymmetric derivatives is one of the most popular topics and typically involves the design of donor-acceptor (D-A) type molecules. Such species shows great adjustability for optoelectronic properties because of their efficient excited-state intramolecular charge transfer (ICT). ${ }^{4-6}$ It is known that long axial asymmetrically pyrene-based derivatives functionalized at the 1-, 3-, 6-, 8-positions can be accessed by an electrophilic substitution reaction due to the HOMOs have largest coefficients, and such species possess outstanding properties. $^{7-10}$ Moreover, $1,6-$ or $1,8-$ disubstituted and 1,3,6,8-tetrasubstituted asymmetric pyrene-based materials appending two or two pairs different groups have been reported with excellent photoelectric properties. ${ }^{1,2}$ However, high chemical activity has led to many challenges such as the formation of numerous isomers that are very difficult to separate. ${ }^{11}$

\footnotetext{
Corresponding author. Fax: +81 95228 8548; e-mail address: yamatot@cc.saga-u.ac.jp
} (T. Yamato)
Interestingly, 2,7-disubstituted pyrene derivatives exhibited distinct difference in their optical behaviour, such as single molecular white emitters, ${ }^{12}$ adjustable redox potentials and frontier orbitals. ${ }^{13-15}$ Recently, a controllable regioselective approach at alternative positions was established by Yamato and co-workers, ${ }^{16}$ which achieved the stepwise functionalization at the K-region (5-, 9-positions) and the active sites (1-, 3-positions). The strategy expands the scope of pyrene-based photoelectric materials. Meanwhile, there has been some significant work based on functionalization along the short axis. Müllen and coworkers opened up new method to functionalize pyrene at the K-region via bromination and presented a few examples possessing long wave emission (> $600 \mathrm{~nm}$ ). ${ }^{17,18}$ There are also a number of reports concerning D- $\pi$-A type pyrenes, such as those obtained by combining 2,7- or 1,8-acceptor moieties with 4,5- donor moieties which led to strongly redshifted absorptions with high molar absorptivities, ${ }^{19-21}$ and a series of green and blue emitters prepared by introducing donor and acceptor groups at the 1,8-positions and 3,6positions, respectively. ${ }^{22,23}$ On the basis of these studies, the possibility of position-dependent photoelectric properties 
inspired our interest to construct $D-\pi$-A type pyrene systems in less explored positional regions.
1

2

3

4

5

6

7

8

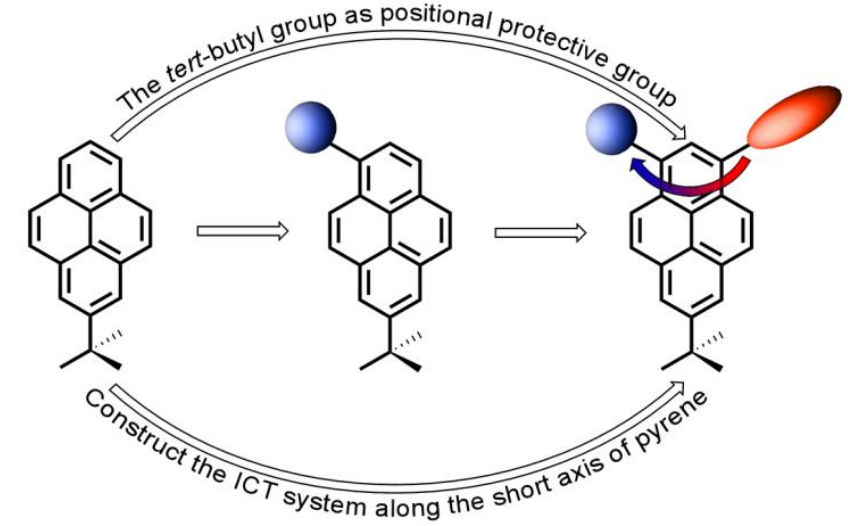

Scheme 1. Illustration of the pyrene-based D- $\pi$-A emitters.

In our previous report, we presented a facile and predictive strategy to tune the emission color by constructing $\mathrm{D}-\pi$-D pyrenes at the $1-, 3$-positions. ${ }^{24}$ Taking account of the above considerations, two 1-donor-3-acceptor pyrenes with tuneable highest occupied molecular orbital (HOMO) and lowest unoccupied molecular orbital (LUMO) levels are presented (Scheme 1). New pyrene chemistry has therefore been developed for the stepwise functionalization at the 1-, 3-positions starting from 7-tert-butylpyrene.

\section{Results and discussion}

\subsection{Synthesis and characterization}

In general, the electrophilic substitution reaction shows high activity at the 1-, 3-, 6-, and 8-positions of pyrene. Thus, various pyrene derivatives ${ }^{1}$ can be easily accessed depending on the experimental conditions. However, it is quite difficult to introduce different substituents selectively at the 1- and 3-positions of pyrene by direct electrophilic aromatic substitution reactions due to the formation of 1,6and 1,8-substituted products. According to previous reports, 7-tert-butyl-1,3-dibromopyrene $3^{25,26}$ can be synthesized from 2-tert-butylpyrene 1 with $\mathrm{Br}_{2}$ at temperatures below $78^{\circ} \mathrm{C}$ based on positional protective strategy by employing a tert-butyl group. However, the sensitivity to experimental conditions leads to the formation of complex by-products, which also limits the synthesis of this kind of compounds to some extent. Previously, we reported that treatment of 2tert-butylpyrene $\mathbf{1}$ with benzyltrimethylammonium tribromide (BTMABr 3 ) (3.5 equiv.) in dry $\mathrm{CH}_{2} \mathrm{Cl}_{2}$ at room temperature to give the desired 1,3-dibromo-7-tertbutylpyrene 3 in good yield $(76 \%)$. And a mixture of $\mathbf{1}$ and $\mathrm{BTMABr}_{3}$ (1.1 equiv.) in $\mathrm{CH}_{2} \mathrm{Cl}_{2}$ at room temperature for 12 $\mathrm{h}$ afforded the desired product 2 in $84 \%$ yield along with recovery of the starting compound 1 and 1,3-dibromo-7-tertbutylpyrene $3 .^{27,28}$ On the other hand, bromination of $\mathbf{1}$ was performed with $N$-bromosuccinimide (NBS) (1.1 equiv.) in THF at room temperature for $12 \mathrm{~h}$, which exclusively afforded 2 in $94 \%$ yield. The 7-tert-butyl-1-arylpyrenes 4 were synthesized from bromide $\mathbf{2}$ with the corresponding arylboronic acid by the Suzuki-Miyaura cross-coupling reaction in good yields. Bromination of $\mathbf{4 a}$ and $\mathbf{4 b}$ with $\mathrm{BTMABr}_{3}$ (1.5 equiv.) in $\mathrm{CH}_{2} \mathrm{Cl}_{2}-\mathrm{MeOH}$ at room temperature for $6 \mathrm{~h}$ occurred selectively at 3-position to afford the desired 1-aryl-3-bromopyrene $\mathbf{5 a}$ and $\mathbf{5 b}$ in 88 and $98 \%$ yields, respectively. The target 1,3-asymmetrically substituted pyrenes $\mathbf{6}$ were synthesize from 5 by Sonogashira coupling reactions with the corresponding arylacetylenes as shown in Scheme 2. In particular, a new pyrene is presented, and the key step of this novel strategy is the bromination reaction at 1 - and 3-positions by employing benzyltrimethylammonium tribromide $\left(\mathrm{BTMABr}_{3}\right)$ and NBS under moderate conditions. All products and intermediates were fully characterized by high-resolution mass spectrometry and NMR spectroscopy (see Figs. S2-10 in the Supporting information). The thermal stabilities of $\mathbf{6}$ were researched by thermogravimetric analysis (TGA) at a heating rate of $10^{\circ} \mathrm{C} \mathrm{min}^{-1}$ under a nitrogen atmosphere (Fig. $\mathrm{S} 11)$. The results showed that emitters 6 exhibited high thermal stabilities $\left(\mathrm{Td}>400{ }^{\circ} \mathrm{C}\right)$, which also suggest great potential application in organic electronics materials. method to introduce the functional groups at the terminal of
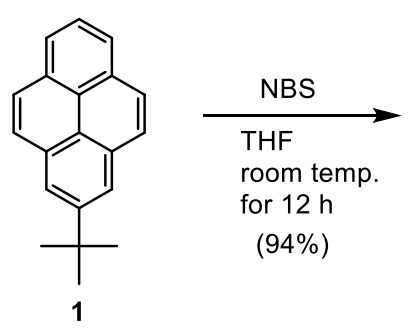<smiles>CC(C)(C)C1=c2c3c(Br)ccc2=CC=C2CCC(=C1)C2=C3</smiles>

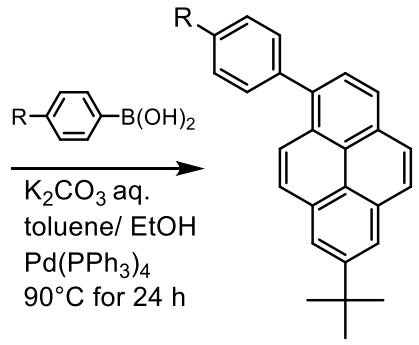

4a: $\mathrm{R}=\mathrm{H}(76 \%)$ 4b: $\mathrm{R}=\mathrm{CHO}(53 \%)$

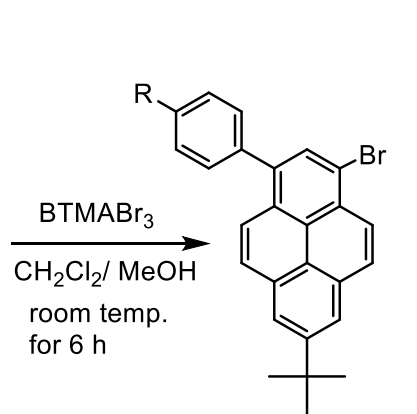<smiles>[R]c1ccc(-c2cc(C#Cc3ccc(N(C)C)cc3)c3ccc4cc(C(C)(C)C)cc5ccc2c3c45)cc1</smiles>

5a: $\mathrm{R}=\mathrm{H}(88 \%)$ 5b: $\mathrm{R}=\mathrm{CHO}(98 \%)$ 6a: $\mathrm{R}=\mathrm{H}(50 \%)$

6b: $\mathrm{R}=\mathrm{CHO}(39 \%)$ 
Scheme 2. Synthetic route to emitters 6.

\subsection{Photophysical properties}

1
Detailed studies of their photophysical properties were performed by comparing with the reference compound of 1,3-diphenyl-7-tert-butylpyrene 7. ${ }^{26}$ As shown in Fig. 1 left and Table 1, the absorption spectra of $\mathbf{6}$ in $\mathrm{CH}_{2} \mathrm{Cl}_{2}$ (DCM) solution exhibit a set of obvious absorption bands at around 270-340 nm with a shoulder band observed at around 400 $\mathrm{nm}$. By comparing the spectrum of reference compound 7 given in Table 1, the absorption bands at short wavelengths benefit from the bathochromic shift of the absorption of the phenyl and pyrene core, which can be ascribed to the intramolecular $\pi-\pi^{*}$ transition of the extended $\pi$-conjugation of alkynyl and phenyl groups, while the low-energy shoulder absorption with high molar absorption coefficients indicates that their excited states possess significant charge transfer absorption associated with the intramolecular charge transfer from the arylethynyl units to the aryl group via the pyrene core. Meanwhile, slightly difference of the shoulder at 400 $\mathrm{nm}$ and obvious difference at around $350 \mathrm{~nm}$ indicated that the strength and region of charge transfer play a significant role for the absorption properties. This indicates that a more efficient excited-state intramolecular charge transfer has occurred in this type of pyrene derivatives.

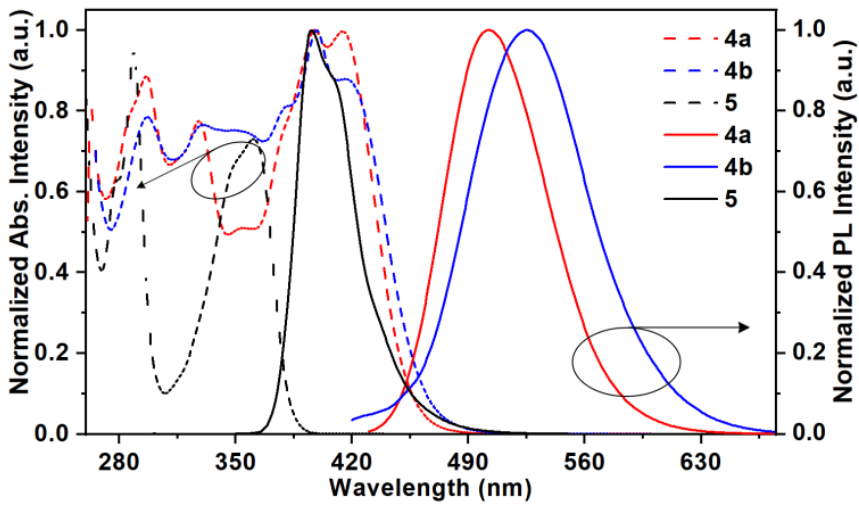

Figure 1. UV-Vis absorption spectra (left arrow) and fluorescence spectra (right arrow) of $\mathbf{6 a}, \mathbf{6 b}$ and 7 in DCM solutions at $\sim 10^{-5}-10^{-7} \mathrm{M}$ at room temperature.

Table 1. Optical absorption and emission spectroscopic data of compounds $6 \mathbf{a}, 6 \mathbf{b}$ and 7. . $^{\text {[a] }}$

\begin{tabular}{|c|c|c|c|c|c|c|c|}
\hline Compounds & $\lambda_{\max } \operatorname{abs}[\mathrm{nm}]^{[\mathrm{b}]}$ & $\lambda_{\max } \mathrm{PL}[\mathrm{nm}]^{[\mathrm{c}]}$ & Stokes-shift [nm] & $\begin{array}{c}\text { HOMO } \\
(\mathrm{eV})\end{array}$ & $\begin{array}{c}\text { LUMO } \\
(\mathrm{eV})\end{array}$ & $\begin{array}{l}\Delta \mathrm{E}^{[\mathrm{d}]} \\
(\mathrm{eV}) \\
\end{array}$ & $\Phi_{F}^{[\mathrm{e}]}$ \\
\hline $6 \mathbf{a}$ & 396 & 502 & 106 & -4.56 & -1.60 & 3.05 & 0.88 \\
\hline $6 \mathbf{b}$ & 398 & 525 & 137 & -4.76 & -1.90 & 2.86 & 0.07 \\
\hline 7 & 360 & 396 & 36 & -5.09 & -1.55 & 3.54 & 0.38 \\
\hline
\end{tabular}

${ }^{a}$ All measurements were performed under degassed conditions. ${ }^{\mathrm{b}} \sim \times 10^{-5} \mathrm{M}$ in $\mathrm{CH}_{2} \mathrm{Cl}_{2}, \lambda_{\text {abs }}$ is the absorption band appearing at the longest wavelength. ${ }^{c} \sim \times 10^{-7} \mathrm{M}$ in $\mathrm{CH}_{2} \mathrm{Cl}_{2}, \lambda_{\text {ex }}$ is the fluorescence band appearing at the shortest wavelength. ${ }^{\mathrm{d}}$ DFT/B3LYP/6-31G* using Gaussian. ${ }^{\mathrm{e}}$ Absolute quantum yield $( \pm 0.01-0.03)$ in dichloromethane.

On the other hand, the emission spectra of emitters 6 present a simple and clear emission band. More specifically, the emission maxima are in the range $502-525 \mathrm{~nm}$ in dilute DCM solution with an obvious red-shift (more than $100 \mathrm{~nm}$ ) compared with compound 7 (396 nm) (Fig. 1 right). Compounds $6 \mathbf{a}$ and $\mathbf{6 b}$ exhibit green emission with peaks at $502 \mathrm{~nm}$ and $525 \mathrm{~nm}$, respectively. The photoluminescence quantum yields of emitters 6 were also recorded, and two compounds exhibit reasonable quantum yields $\left(\Phi_{\mathrm{F}}\right)$, especially for $\mathbf{6 a}$, the $\Phi_{\mathrm{F}}$ in DCM solution up to $88 \%$, showing a substantial enhancement compared to $7\left(\Phi_{\mathrm{F}}=\right.$ $38 \%$ ), which benefit from the expended $\pi$ conjugated system. On the other hand, the $\Phi_{\mathrm{F}}$ value of $\mathbf{6 b}$ shows increasing trend due to the influence of distinct intramolecular charge transfer. As expected, based on our novel design strategy of short axially asymmetrically 1-donor-3-acceptor pyrenes, two compounds exhibit efficient color-tunable properties.

In order to investigate the emission mechanism of these two short axially D- $\pi$-A type pyrene emitters, solvatochromism was carried out in solvents of different polarities (dimethyl formamide (DMF), tetrahydrofuran (THF), dichloromethane (DCM), 1,4-dioxane, and cyclohexane). Pertinent data for the absorption and emission spectra are shown in Fig. 2 and Figs. S12-17). The absorption spectra of compounds of type $\mathbf{6}$ all present zero or minimum solvent dependence. In sharp contrast, significant solvatochromism was observed for the emission spectra of both emitters. Both two compounds $\mathbf{6 a}-\mathbf{b}$ exhibited significant bathochromic shift for their emission spectra in different solution, as large as $116 \mathrm{~nm}$, and $95 \mathrm{~nm}$ for $6 \mathbf{a}$, and $\mathbf{6 b}$, respectively. Based on the case study of $\mathbf{6 a}$, as depicted in Fig. 2b, which exhibited significant color change from sky-blue to yellow from cyclohexane solution to DMF solution. The results further indicate that emitters 6 are tuneable and favorable luminescent materials. Meanwhile, this result of solvatochromism was further elucidated by the relationship between the Lippert equation and the Stokes shifts in various solvents. ${ }^{29,30}$ The LippertMataga plots present linear correlation together with a high slope value, which indicate that the dipolar moment of the intramolecular excited state is larger than the ground state because of the substantial charge redistribution. And the value of the slope for $\mathbf{6 a}$ (12802), and $\mathbf{6 b}$ (10529) is far larger than that for 7 (-200). Moreover, compared with the other D- $\pi$-A systems, the slope of the fitting lines for this project are larger than most reported results, ${ }^{6,31}$ which is mainly depended on their dissimilar intramolecular charge transfer effectiveness and pathways of the 1-donor-3acceptor pyrene system. The other crucial factor, the twisted intramolecular charge transfer (TICT), might also play an important role in solution state due to the 4-N,Ndimethylaminophenyl moiety. ${ }^{32}$ As a control, comparing 
with other reported asymmetrically pyrene derivatives with phenyl groups and aryne groups, ${ }^{16,33}$ high tunability and more distinct charge separations were observed by

1

2

3

4

5

6

7

8

9

10

11

12

13

14

15

16
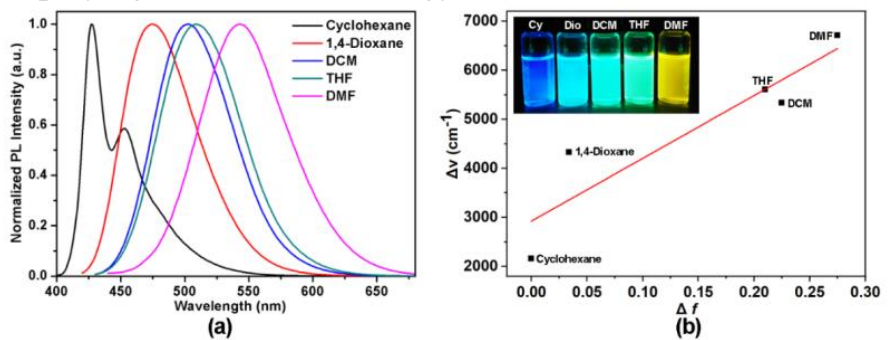

Figure 2. (a) Emission spectra of $6 \mathbf{a}$ in cyclohexane, 1,4-dioxane, THF, DCM, and DMF at room temperature; (b) Lippert-Mataga plots for compound $\mathbf{6 a}$.

\subsection{Quantum chemistry calculations}

To investigate the orbital energies, electron densities, electronic structures of the highest occupied molecular orbital (HOMO) and lowest unoccupied molecular orbital (LUMO) states of the compounds $\mathbf{6}$ and $\mathbf{7}$, as well as to elucidate the photophysical characteristics, density functional theory (DFT) calculations were carried out on the two compounds at the B3LYP/6-31G* level. In general, acceptor groups have an effect on the LUMOs because they are prone to accept electrons, donor groups on the other hand can provide a significant contribution to the HOMOs because they are prone to donate electrons. ${ }^{34}$ For this kind of donor- $\pi$-acceptor (D- $\pi$-A) structures, the energy gaps of these new emitters can be significantly tuned compared with the naked components. As depicted in Fig. 3, the significant difference of distribution of LUMOs and HOMOs of emitters 6 result from the presence of the strong electrondonating nature of the $N, N$-dimethylaminophenyl group, ${ }^{33}$ and especially for compound $\mathbf{6 b}$, the efficient electronwithdrawing nature of the formyl group provided energetically enhanced LUMOs, which are mainly distributed over the pyrene core and 4-formylphenyl substituents. These results of theoretical calculations indicating the emitters 6 allow them to exhibit enhanced ICT character compared with $\mathbf{7}$, the fluorescent behaviour is sensitive to structural change, which impacts on the distribution of the LUMOs and HOMOs, particularly polarity ${ }^{35}$ which is consistent with the experimental results, such as emission spectra, solvatochromism.

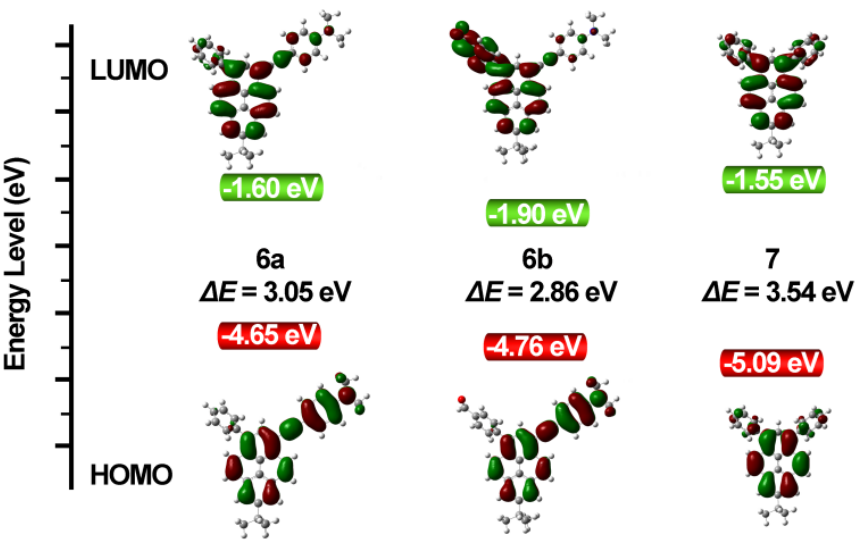

Figure 3. HOMO/LUMO energy levels and frontier molecular orbitals obtained from DFT calculations on $\mathbf{6 a}, \mathbf{6 b}$ and 7 with optimized geometries. $\Delta E$ is an energy bandgap of these three compounds estimated from difference between the HOMO and LUMO values.

\section{Conclusion}

In summary, two novel D- $\pi$-A emitters were prepared by a stepwise bromination reaction, a Suzuki-Miyaura crosscoupling reaction, and a Sonogashira coupling reaction in reasonable yield. Depending on the electronwithdrawing/donating groups along the short axis, the theoretical and experimental results of $\mathbf{6}$ exhibited an obvious adjustability of color and other properties. Two compounds exhibit high thermal stability and good solubility. The present work not only opens up new avenues to explore a novel functionalization strategy and to broaden the scope for constructing efficient pyrene-based optoelectronic materials. Ongoing works are focusing on this type of emitter and will be published soon.

\section{Experimental section}

All melting points are uncorrected. All reactions were performed under a dry $\mathrm{N}_{2}$ atmosphere. Solvents were Guaranteed reagent (GR) for dimethylformamide (DMF), tetrahydrofuran (THF), dichloromethane (DCM), 1,4dioxane, and cyclohexane, and stored over molecular sieves. Other reagents were obtained commercially and used without further purification. Reactions were monitored using thin layer chromatography (TLC). Commercial TLC plates (Merck Co.) were developed and the spots were identified under UV light at 254 and $365 \mathrm{~nm}$. Column chromatography was performed on silica gel $60(0.063-0.200 \mathrm{~mm})$. All synthesized compounds were characterized using ${ }^{1} \mathrm{H} /{ }^{13} \mathrm{C}$ NMR spectroscopy, and by HRMS (FAB) mass analysis. Fluorescence spectroscopic studies were performed in various organic solvents in a semimicro fluorescence cell (Hellma®, 104F-QS, $10 \times 4 \mathrm{~mm}, 1400 \mu \mathrm{L}$ ) with a Varian Cary Eclipse spectrophotometer. Fluorescence quantum yields were measured using absolute methods.

\subsection{General procedure for the systhesis of 2}

$N$-Bromosucccinimide (NBS) (195.8 mg, $1.1 \mathrm{mmol}$ ) was slowly added to a solution of 2-tert-butylpyrene $\mathbf{1}(258 \mathrm{mg}, 1 \mathrm{mmol})$ in dry tetrahydrofuran $(10 \mathrm{~mL})$ at $0{ }^{\circ} \mathrm{C}$ under a nitrogen atmosphere. The resulting mixture was allowed to slowly warm up to room temperature and stirred overnight. The reaction mixture was quenched with $\mathrm{Na}_{2} \mathrm{~S}_{2} \mathrm{O}_{3}$ and extracted with $\mathrm{CH}_{2} \mathrm{Cl}_{2}(2 \times 20 \mathrm{~mL})$. The combined organic extracts were dried with anhydrous $\mathrm{MgSO}_{4}$ and evaporated. The residue was crystallized from hexane to give pure 1-bromo-7-tert-butylpyrene $\mathbf{2}$ in as white crystals (318 mg, 94\%). The ${ }^{1} \mathrm{H}$ NMR spectrum completely agreed with the reported values. ${ }^{27}$

\subsection{The Suzuki-Miyaura coupling reaction towards the synthesis of $4 \boldsymbol{a}-\boldsymbol{b}$}

A mixture of 1-bromo-7-tert-butylpyrene $2(675 \mathrm{mg}, 2.0$ $\mathrm{mmol})$, ethanol $(10 \mathrm{~mL})$ and arylboronic acid $(4.0 \mathrm{mmol})$ in toluene $(40 \mathrm{~mL})$ and at room temperature was stirred under argon, and $\mathrm{Pd}\left(\mathrm{PPh}_{3}\right)_{4}(35 \mathrm{mg}, 1.5 \mathrm{~mol} \%)$ and a $2 \mathrm{M}$ aqueous 
solution of $\mathrm{Na}_{2} \mathrm{CO}_{3}(40 \mathrm{~mL})$ were added. After the mixture was stirred for $30 \mathrm{~min}$ under argon at room temperature, the mixture was heated to $90{ }^{\circ} \mathrm{C}$ with stirring for $24 \mathrm{~h}$. The mixture was cooled to room temperature, and the mixture was quenched with water, extracted with $\mathrm{CH}_{2} \mathrm{Cl}_{2}(2 \times 100$ $\mathrm{mL}$ ), and washed with water and brine. The organic extracts were dried with $\mathrm{MgSO}_{4}$ powder and the solvent was evaporated. The crude reaction mixture, which was further describe as indicated in the individual cases

\subsection{Synthesis of 7-tert-butyl-1-phenylpyrene (4a)}

A similar procedure with phenylboronic acid $(488 \mathrm{mg}, 4.0$ mmol), was followed for the synthesis of $\mathbf{4 a} .^{36} \mathbf{4 a}$ was obtained as white solid (recrystallized from hexane- $\mathrm{CHCl}_{3}$ (9:1); $510 \mathrm{mg}, 76 \%) .{ }^{1} \mathrm{H} \mathrm{NMR}\left(400 \mathrm{MHz}, \mathrm{CDCl}_{3}\right) \delta(\mathrm{ppm})=$ $1.58(\mathrm{~s}, 9 \mathrm{H}, t \mathrm{Bu}), 7.48(\mathrm{~m}, 1 \mathrm{H}, \operatorname{Ar}-H), 7.56(\mathrm{t}, J=7.4,2 \mathrm{H}$, $\operatorname{Ar}-H), 7.64(\mathrm{~d}, J=7.7 \mathrm{~Hz}, 2 \mathrm{H}, \operatorname{Ar}-H), 7.94(\mathrm{~d}, J=7.8 \mathrm{~Hz}$, $1 \mathrm{H}$, pyrene- $H), 8.00(\mathrm{~d}, J=9.3 \mathrm{~Hz}, 1 \mathrm{H}$, pyrene- $H), 8.07(\mathrm{~d}$, $J=1.5 \mathrm{~Hz}, 2 \mathrm{H}$, pyrene- $H), 8.14(\mathrm{~d}, J=9.3 \mathrm{~Hz}, 1 \mathrm{H}$, pyrene$H), 8.18(\mathrm{~d}, J=8.0 \mathrm{~Hz}, 1 \mathrm{H}$, pyrene- $H), 8.21(\mathrm{~d}, J=9.3 \mathrm{~Hz}$, $1 \mathrm{H}$, pyrene- $H$ ), 8.22 (d, $J=9.3 \mathrm{~Hz}, 1 \mathrm{H}$, pyrene- $H$ ).

\subsection{Synthesis of 7-tert-butyl-1-(4-formylphenyl)pyrene (4b)}

A similar procedure with 4-formylphenylboronic acid $(600 \mathrm{mg}$, $4.0 \mathrm{mmol}$ ), was followed for the synthesis of $\mathbf{4 b}$. $\mathbf{4 b}$ was obtained as yellow solid (recrystallized from hexane- $\mathrm{CHCl}_{3}(6: 1) ; 379$ mg, 53\%). M.p. $134-136{ }^{\circ} \mathrm{C} ;{ }^{1} \mathrm{H}$ NMR $\left(400 \mathrm{MHz}, \mathrm{CDCl}_{3}\right) \delta$ $(\mathrm{ppm})=1.59(\mathrm{~s}, 9 \mathrm{H}, t \mathrm{Bu}), 7.83(\mathrm{~d}, J=8.0 \mathrm{~Hz}, 2 \mathrm{H}$, Ar- $H), 7.94$ $(\mathrm{d}, J=7.8 \mathrm{~Hz}, 2 \mathrm{H}, \mathrm{Ar}-H), 8.04$ (d, $J=9.3 \mathrm{~Hz}, 1 \mathrm{H}, \mathrm{Ar}-H), 8.06$ $8.12(\mathrm{~m}, 5 \mathrm{H}$, pyrene- $H), 8.19-8.25(\mathrm{~m}, 2 \mathrm{H}$, pyrene- $H), 10.16(\mathrm{~s}$, $1 \mathrm{H}, \mathrm{CHO}), \mathrm{FAB}-\mathrm{MS}: \mathrm{m} / \mathrm{z}$ calcd for $\mathrm{C}_{27} \mathrm{H}_{22} \mathrm{O} 362.1671\left[\mathrm{M}^{+}\right]$; found $362.1670\left[\mathrm{M}^{+}\right]$

\subsection{Synthesis of 7-tert-butyl-1-phenyl-3-bromopyrene (5a)}

A Compound 7-tert-butyl-1-phenylpyrene 4a (334 mg, 1.0 mmol) was added in $\mathrm{CH}_{2} \mathrm{Cl}_{2}(9 \mathrm{~mL})$ and $\mathrm{MeOH}(25 \mathrm{~mL})$, and the mixture was stirred under argon atmosphere at $0{ }^{\circ} \mathrm{C}$. After 30 min, BTMABr $_{3}(585 \mathrm{mg}, 1.5 \mathrm{mmol})$ was added. The resulting mixture was stirred for $6 \mathrm{~h}$ at room temperature under argon. The mixture was extracted with $\mathrm{CH}_{2} \mathrm{Cl}_{2}(2 \times 50 \mathrm{~mL})$, and the combined extracts were washed with water and brine, dried with $\mathrm{MgSO}_{4}$ powder and concentrated. The residue was chromatographed over silica gel (Wako C-300, $200 \mathrm{~g}$ ) with hexane- $\mathrm{CHCl}_{3}(9: 1)$ as eluent to give a white solid (366 mg, 88\%). M.p. $110-112{ }^{\circ} \mathrm{C} ;{ }^{1} \mathrm{H}$ NMR $\left(400 \mathrm{MHz}, \mathrm{CDCl}_{3}\right) \delta(\mathrm{ppm})=$ $1.59(\mathrm{~s}, 9 \mathrm{H}, t \mathrm{Bu}), 7.47-7.62(\mathrm{~m}, 5 \mathrm{H}, \operatorname{Ar}-H), 7.94(\mathrm{~d}, J=8.0 \mathrm{~Hz}$, $1 \mathrm{H}$, pyrene- $H), 8.01(\mathrm{~d}, J=9.2 \mathrm{~Hz}, 1 \mathrm{H}$, pyrene- $H), 8.08(\mathrm{~d}, J=$ $9.3 \mathrm{~Hz}, 1 \mathrm{H}$, pyrene- $H$ ), $8.17(\mathrm{~d}, J=9.2 \mathrm{~Hz}, 1 \mathrm{H}$, pyrene- $H$ ), $8.20-8.24(\mathrm{~m}, 2 \mathrm{H}$, pyrene- $H), 8.27(\mathrm{~s}, 1 \mathrm{H}$, pyrene- $H), 8.43(\mathrm{~d}, J$ $=9.2,1 \mathrm{H}$, pyrene- $H$ ). FAB-MS: $m / z$ calcd for $\mathrm{C}_{26} \mathrm{H}_{21} \mathrm{Br} 412.0827$ $\left[\mathrm{M}^{+}\right]$; found $412.0827\left[\mathrm{M}^{+}\right]$.

\subsection{Synthesis of 7-tert-butyl-1-(4-formylphenyl)-3-bromopyrene} $(5 b)$

A Compound 7-tert-butyl-1-(4-formylphenyl)pyrene $\mathbf{4 b}$ (200 mg, $0.56 \mathrm{mmol})$ was added in $\mathrm{CH}_{2} \mathrm{Cl}_{2}(5 \mathrm{~mL}), \mathrm{MeOH}(15 \mathrm{~mL})$, and the mixture was stirred under argon atmosphere at $0{ }^{\circ} \mathrm{C}$. After 30 min, $\mathrm{BTMABr}_{3}(328 \mathrm{mg}, 0.84 \mathrm{mmol})$ was added. The resulting mixture was stirred for $6 \mathrm{~h}$ at room temperature under argon. The mixture was extracted with $\mathrm{CH}_{2} \mathrm{Cl}_{2}(2 \times 30 \mathrm{~mL})$, and the combined extracts were washed with water and brine, dried with $\mathrm{MgSO}_{4}$ powder and concentrated. The residue was chromatographed over silica gel (Wako C-300, $150 \mathrm{~g}$ ) with hexane- $\mathrm{CHCl}_{3}(7: 1)$ as eluent to give a pale-yellow solid (240 mg, 98\%). M.p. ${ }^{122-124}{ }^{\circ} \mathrm{C} ;{ }^{1} \mathrm{H}$ NMR (400 MHz, $\left.\mathrm{CDCl}_{3}\right) \delta$ $(\mathrm{ppm})=1.52(\mathrm{~s}, 9 \mathrm{H}, t \mathrm{Bu}), 7.73(\mathrm{~d}, J=7.7 \mathrm{~Hz}, 2 \mathrm{H}$, Ar- $H), 7.97$ $(\mathrm{d}, J=7.7 \mathrm{~Hz}, 2 \mathrm{H}, \operatorname{Ar}-H), 8.02(\mathrm{~d}, J=7.9 \mathrm{~Hz}, 2 \mathrm{H}$, pyrene- $H$ ), $8.15(\mathrm{~d}, J=7.9 \mathrm{~Hz}, 2 \mathrm{H}$, pyrene- $H), 8.19$ (s, $1 \mathrm{H}$, pyrene- $H), 8.24$ (s, $1 \mathrm{H}), 8.38(\mathrm{~d}, J=9.3 \mathrm{~Hz}, 1 \mathrm{H}$, pyrene- $H), 10.10$ (s, $1 \mathrm{H}, \mathrm{CHO})$. ${ }^{13} \mathrm{C}$ NMR $\left(100 \mathrm{MHz}, \mathrm{CDCl}_{3}\right) \delta(\mathrm{ppm})=192.13,150.26,146.45$, $136.65,135.57,131.36,131.25,130.98,130.82,130.03,129.82$, $129.55,128.65,127.84,126.25,125.89,124.42,123.54,123.40$, 122.56, 119.62, 35.43, 32.00. FAB-MS: $m / z$ calcd for $\mathrm{C}_{27} \mathrm{H}_{21} \mathrm{BrO}$ $440.0776\left[\mathrm{M}^{+}\right]$; found $440.0775\left[\mathrm{M}^{+}\right]$.

\subsection{Synthesis of 7-tert-butyl-1-phenyl-3-(4-N,N- dimetylaminophenylethynyl)pyrene $(\boldsymbol{6} \boldsymbol{a})$}

A mixture of 7-tert-butyl-1-phenyl-3-bromopyrene 5a (150 mg, $0.36 \mathrm{mmol}), \mathrm{N}, \mathrm{N}$-dimetylaminophenyl acetylene $(105 \mathrm{mg}, 0.73$ $\mathrm{mmol}), \mathrm{PPh}_{3}$ (9 mg, $\left.0.036 \mathrm{mmol}\right), \mathrm{CuI}(7 \mathrm{mg}, 0.36 \mathrm{mmol})$, $\mathrm{PdCl}_{2}\left(\mathrm{PPh}_{3}\right)_{3}(13 \mathrm{mg}, 0.036 \mathrm{mmol})$ were added to a degassed solution of DMF $(8 \mathrm{~mL})$ and $\mathrm{Et}_{3} \mathrm{~N}(8 \mathrm{~mL})$. The resulting mixture was stirred at $100{ }^{\circ} \mathrm{C}$ for $24 \mathrm{~h}$. After it was cooled to room temperature, the reaction was quenched with water. The mixture was extracted with $\mathrm{CH}_{2} \mathrm{Cl}_{2}(2 \times 50 \mathrm{~mL})$, the organic layer was washed with water $(2 \times 30 \mathrm{~mL})$ and brine $(30 \mathrm{~mL})$, and then the solution was dried $\left(\mathrm{MgSO}_{4}\right)$, and evaporated. The residue was purified by column chromatography eluting with a hexane$\mathrm{CHCl}_{3}(3: 2)$ mixture to give $\mathbf{6 a}$ as a yellow crystalline powder (86.1 mg, 50\%). M.p. 206-208 ${ }^{\circ} \mathrm{C} ;{ }^{1} \mathrm{H}$ NMR (400 MHz, $\left.\mathrm{CDCl}_{3}\right) \delta$ $(\mathrm{ppm})=1.59(\mathrm{~s}, 9 \mathrm{H}, t \mathrm{Bu}), 3.03\left(\mathrm{~s}, 6 \mathrm{H}, \mathrm{NMe} e_{2}\right), 6.74(\mathrm{~d}, J=7.2$ $\mathrm{Hz}, 2 \mathrm{H}, \mathrm{Ar}-H), 7.49$ (d, $J=7.0 \mathrm{~Hz}, 1 \mathrm{H}, \mathrm{Ar}-H), 7.54-7.62(\mathrm{~m}, 4 \mathrm{H}$, Ar- $H$ ), $7.65(\mathrm{~d}, J=7.1 \mathrm{~Hz}, 2 \mathrm{H}, \operatorname{Ar}-H), 7.99(\mathrm{~d}, J=9.0 \mathrm{~Hz}, 1 \mathrm{H}$, pyrene- $H), 8.10(\mathrm{~d}, J=8.8 \mathrm{~Hz}, 1 \mathrm{H}$, pyrene- $H), 8.17(\mathrm{~m}, 3 \mathrm{H}$, pyrene- $H$ ), $8.25(\mathrm{~s}, 1 \mathrm{H}$, pyrene- $H), 8.68(\mathrm{~d}, J=8.9 \mathrm{~Hz}, 1 \mathrm{H}$, pyrene- $H) .{ }^{13} \mathrm{C}$ NMR $\left(100 \mathrm{MHz}, \mathrm{CDCl}_{3}\right) \delta(\mathrm{ppm})=149.50$, $140.86,137.33,133.00,131.50,131.15,130.81,130.67,128.49$, 128.27, 128.06, 127.45, 125.83, 125.22, 122.91, 122.59, 118.49, 112.05, 96.57, 87.72, 40.44, 35.36, 32.04. FAB-MS: $\mathrm{m} / \mathrm{z}$ calcd

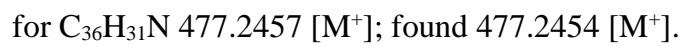

\subsection{Synthesis of 7-tert-butyl-1-(4-formylphenyl)-3-(4- $N, N$ - dimetylaminophenylethynyl)pyrene $(\boldsymbol{6} \boldsymbol{b})$}

A mix A mixture of 7-tert-butyl-1-(4-formylphenyl)-3bromopyrene $\mathbf{5 b}(120 \mathrm{mg}, 0.27 \mathrm{mmol}), \mathrm{N}, \mathrm{N}$-dimetylaminophenyl acetylene (78 mg, $0.54 \mathrm{mmol}), \mathrm{PPh}_{3}(6.7 \mathrm{mg}, 0.027 \mathrm{mmol}), \mathrm{CuI}$ (5 mg, $0.27 \mathrm{mmol}), \mathrm{PdCl}_{2}\left(\mathrm{PPh}_{3}\right)_{3}(10 \mathrm{mg}, 0.027 \mathrm{mmol})$ were added to a degassed solution of DMF $(6 \mathrm{~mL})$ and $\mathrm{Et}_{3} \mathrm{~N}(6 \mathrm{~mL})$. The resulting mixture was stirred at $100{ }^{\circ} \mathrm{C}$ for $24 \mathrm{~h}$. After it was cooled to room temperature, the reaction was quenched with water. The mixture was extracted with $\mathrm{CH}_{2} \mathrm{Cl}_{2}(2 \times 40 \mathrm{~mL})$, the organic layer was washed with water $(2 \times 30 \mathrm{~mL})$ and brine $(30$ $\mathrm{mL})$, and then the solution was dried $\left(\mathrm{MgSO}_{4}\right)$, and evaporated. The residue was purified by column chromatography eluting with a hexane- $\mathrm{CHCl}_{3}(1: 1)$ mixture to give $\mathbf{6} \mathbf{b}$ as an orange crystalline powder (53.5 mg, 39\%). M.p. $255-257{ }^{\circ} \mathrm{C}$; ${ }^{1} \mathrm{H}$ NMR $(400 \mathrm{MHz}$, $\left.\mathrm{CDCl}_{3}\right) \delta(\mathrm{ppm})=1.60(\mathrm{~s}, 9 \mathrm{H}, t \mathrm{Bu}), 3.04\left(\mathrm{~s}, 6 \mathrm{H}, \mathrm{NMe} e_{2}\right), 6.74(\mathrm{~d}$, $J=7.5 \mathrm{~Hz}, 2 \mathrm{H}, \operatorname{Ar}-H), 7.60(\mathrm{~d}, J=8.9 \mathrm{~Hz}, 2 \mathrm{H}, \operatorname{Ar}-H), 7.83$ (d, $J$ $=7.8 \mathrm{~Hz}, 2 \mathrm{H}, \operatorname{Ar}-H), 8.03(\mathrm{~s}, 2 \mathrm{H}$, pyrene- $H), 8.07(\mathrm{~d}, J=7.8 \mathrm{~Hz}$, 
$2 \mathrm{H}, \operatorname{Ar}-H), 8.09$ (s, $1 \mathrm{H}$, pyrene- $H), 8.18(\mathrm{~d}, J=10.2 \mathrm{~Hz}, 1 \mathrm{H}$, pyrene- $H$ ), $8.22(\mathrm{~s}, 1 \mathrm{H}$, pyrene- $H), 8.29(\mathrm{~s}, 1 \mathrm{H}$, pyrene- $H), 8.69$ $(\mathrm{d}, J=10.0 \mathrm{~Hz}, 1 \mathrm{H}$, pyrene- $H), 10.16(\mathrm{~s}, 1 \mathrm{H}, \mathrm{CHO}) .{ }^{13} \mathrm{C} \mathrm{NMR}$

$\left(100 \mathrm{MHz}, \mathrm{CDCl}_{3}\right) \delta(\mathrm{ppm})=192.23,150.41,149.78,147.40$ $135.65,135.39,133.03,131.48,131.39,131.34,130.90,131.07$, $130.28,129.95,128.77,128.62,127.84,125.79,125.07,124.52$, $123.32,122.99,122.92,118.75,112.04,110.14,97.06,86.58$, $40.38,35.40,32.02$. FAB-MS: $m / z$ calcd for $\mathrm{C}_{37} \mathrm{H}_{31} \mathrm{NO} 505.2406$ $\left[\mathrm{M}^{+}\right]$; found $505.2357\left[\mathrm{M}^{+}\right]$.

\section{Acknowledgments}

This work was performed under the Cooperative Research Program of "Network Joint Research Center for Materials and Devices (Institute for Materials Chemistry and Engineering, Kyushu University)". We would like to thank the Natural Science Foundation of Shandong Province (Grant No. ZR2019BB067) The EPSRC is thanked for an overseas travel grant to C.R. (EP/R023816/1).

\section{Supplementary data}

Electronic Supplementary Information (ESI) available: Details of ${ }^{1} \mathrm{H},{ }^{13} \mathrm{C}$ NMR for compounds $\mathbf{4 ,} 5$ and $\mathbf{6}$; Photophysical properties of $\mathbf{6}$ and 7. For ESI and other electronic format see DOI: 10.1039/x0xx00000x

\section{References and notes}

1. Figueira-Duarte, T. M.; Müllen K. Chem. Rev. 2011, 111, 7260-7314.

2. Feng, X.; Hu, J.-Y.; Redshaw, C.; Yamato, T. Chem. Eur. J. 2016, 22, 11898-11916.

3. Islam, M. M.; Hu, Z.; Wang, Q. S.; Redshaw, C.; Feng, X. Mater. Chem. Front. 2019, 23, 762-781.

4. Casas-Solvas, J. M.; Howgego, J. D.; Davis, A. P. Org. Biomol. Chem. 2014, 12, 212-232.

5. Levi, L.; Müller, T. J. J. Chem. Soc. Rev. 2016, 45, 2825-2846.

6. Merz, J.; Dietz, M.; Vonhausen, Y.; Wöber, F.; Friedrich, A.; Sieh, D.; Krummenacher, I.; Braunschweig, H.; Moos, M.; Holzapfel, M.; Lambert, C.; Marder, T. B. Chem. Eur. J. 2020, 26, 438-453.

7. Oh, J.-W.; Lee, Y. O.; Kim, T. H. Ko, K. C.; Lee, J. Y.; Kim, H.; Kim, J. S. Angew. Chem. Int. Ed. 2009, 48, 2522-2524.

8. Niko, Y.; Kawauchi, S.; Konishi, G-i. Chem. Eur. J. 2013, 19, 9760-9765.

9. Wu, Y.; Wang, J.; Zeng, F.; Huang, S.; Huang, J.; Xie, H.; Yu, C.; Wu, S. ACS Appl. Mater. Interfaces 2016, 8,1511-1519.

10. Zych, D. Molecules 2019, 24, 2551-2583.

11. Niko, Y.; Sasaki, S.; Narushima, K.; Sharma, D. K. Vacha, M.; Konishi, G.-I. J. Org. Chem. 2015, 80,10794-10805.

12. Feng, X.; Qi. C.; Feng, H.-T.; Zhao, Z.; Sung, H. H. Y.; Williams, L. D.; Kwok, R. T. K.; Lam, J. W. Y.; Qin, A.; Tang, B. Z. Chem. Sci. 2018, 9, 5679-5687.

13. Merz, J.; Fink, J.; Friedrich, A.; Krummenacher, I.; Al Mamari, H. H.; Lorenzen, S.; Haehnel, M.; Eichhorn, A.; Moos, M.; Holzapfel, M.; Braunschweig, H.; Lambert, C.; Steffen, A.; Ji, L.; Marder, T. B. Chem. Eur. J. 2017, 23, 13164-13180.

14. Ji, L.; Lorbach, A.; Edkins, R. M.; Marder, T. B. J. Org. Chem. 2015, 80, 5658-5665.

15. Crawford, A. G.; Dwyer, A.D.; Liu, Z.; Steffen, A.; Beeby, A.; Pålsson, L.-O.; Tozer, D. J.; Marder, T. B. J. Am. Chem. Soc. 2011, 133, 13349-13362.

16. Wang, C. Z.; Feng, X.; Kowser, Z.; Wu, C.; Akther, T.; Elsegood M. R. J.; Redshaw, C.; Yamato, T. Dyes Pigm. 2018, 153, 125131.

17. Zöphel, L.; Beckmann, D.; Enkelmann, V.; Chercka, D.; Rieger, R.; Müllen, K. Chem. Commun. 2011, 47, 6960-6962.

18. Zöphel, L.; Enkelmann, V.; Müllen, K. Org. Lett. 2013, 15, 804807.

19. Keller, S. N.; Veltri, N. L.; Sutherland, T. C. Org. Lett. 2013, 15, 4798-4801.
20. Keller, S. N.; Bromby, A. D. Sutherland, T. C. Eur. J. Org. Chem. 2017, 3980-3985.

21. Hogan, D. T.; Gelfand, B. S.; Spasyuk, D. M.; Sutherland, T. C. Mater. Chem. Front. 2020, 4, 268-276.

22. Zhang, R.; Zhao, Y.; Zhang, T.; Xu, L.; Ni, Z. Dyes Pigm. 2016, 130, 106-115.

23. Zhang, R.; Sun, H.; Zhao, Y.; Tang, X.; Ni, Z. Dyes Pigm. 2018,152, 1-13.

24. Wang, C. Z.; Ichiyanagi, H.; Sakaguchi, K.; Feng, X.; Elsegood, M. R. J.; Redshaw, C.; Yamato, T. J. Org. Chem. 2017, 82, 1767182 .

25. Figueira-Duarte, T. M.; Simon, S. C.; Wagner, M.; Druzhinin, S. I.; Zachariasse, K. A.; Mullen, K. Angew. Chem. Int. Ed. 2008, 47, 10175-10178

26. Feng, X.; Hu, J.-Y.; Yi, L.; Seto, N.; Tao, Z.; Redshaw, C.; Elsegood, M. R. J.; Yamato, T. Chem. Asian. J. 2012, 7, 28542863.

27. Feng, X.; Hu, J.-Y.; Tomiyasu, H.; Tao, Z.; Redshaw, C.; Elsegood, M. R. J.; Horsburgh, L.; Teat, S. J.; Wei, X. F.; Yamato, T. RSC Adv. 2015, 5, 8835-8848.

28. Wang, C. Z.; Do, J. H.; Akther, T.; Feng, X.; Matsumoto, T.; Tanaka, J.; Redshaw, C.; Yamato, T. J. Lumin. 2017, 188, 388393.

29. Lippert, V. E.; Naturforsch, Z. Phys. Sci. 1955, 10, 541-545.

30. Mataga, N.; Kaifu, Y.; Koizumi, M. Bull Chem. Soc. Jpn. 1956, $29,465-470$

31. Liu, R.; Ran, H.; Zhao, Z.; Yang, X.; Zhang, J.; Chen, L.; Sun, H.; Hu, J.-Y. ACS Omega. 2018, 3, 5866-5875.

32. Yan, Z. Q.; Yang, Z. Y.; Wang, H.; Li, A. W.; Wang, L. P.; Yang, H. Gao, B. R. Spectrochim Acta: Mol. Biomol. Spectr. 2011, 78, $1640-1645$.

33. Wang, C. Z.; Zhan, R.; Sakaguchi, K.; Feng, X.; Yu, X.; Elsegood, M. R. J.; Teat, S. J.; Redshaw, C.; Yamato, T. ChemPhotoChem. 2018, 2, 749-756.

34. Jérome, D.; Schulz, H. J. Advances in Physics. 2002, 51, 293-479.

35. Sasaki, S.; Drummen, G.; Konishi, G-i. J. Mater. Chem. C. 2016, 4, 2731-2743.

36. Sumi, K.; Niko, Y.; Tokumaru, K.; Konishi, G-I. Chem. Commun. 2013, 49, 3893-3895. 


\section{Graphical Abstract}

2

3

4

5

\section{Short axially asymmetrically 1, 3-disubstituted pyrene-based color-tunable emitters: Synthesis, characterization and optical properties}

Chuan-Zeng Wang ${ }^{a, b}$, Zi-Jin Pang $^{a}$, Ze-Dong Yu ${ }^{a}$, Zhao-Xuan Zeng ${ }^{a}$, Wen-Xuan Zhao ${ }^{a}$, Zi-Yan Zhou ${ }^{a} *$, Carl Redshaw $^{c}$, Takehiko Yamato ${ }^{b, *}$

School of Chemical Engineering, Shandong University of Technology, Zibo 255049, P. R. China,

E-mail:zyzhou@sdut.edu.cn

8 Department of Applied Chemistry, Faculty of Science and Engineering, Saga University, Honjo-machi 1, Saga, 19 840-8502 Japan,E-mail: yamatot@cc.saga-u.ac.jp

$2 \Theta$ Department of Chemistry, The University of Hull, Cottingham Road, Hull, Yorkshire, HU6 7RX, UK

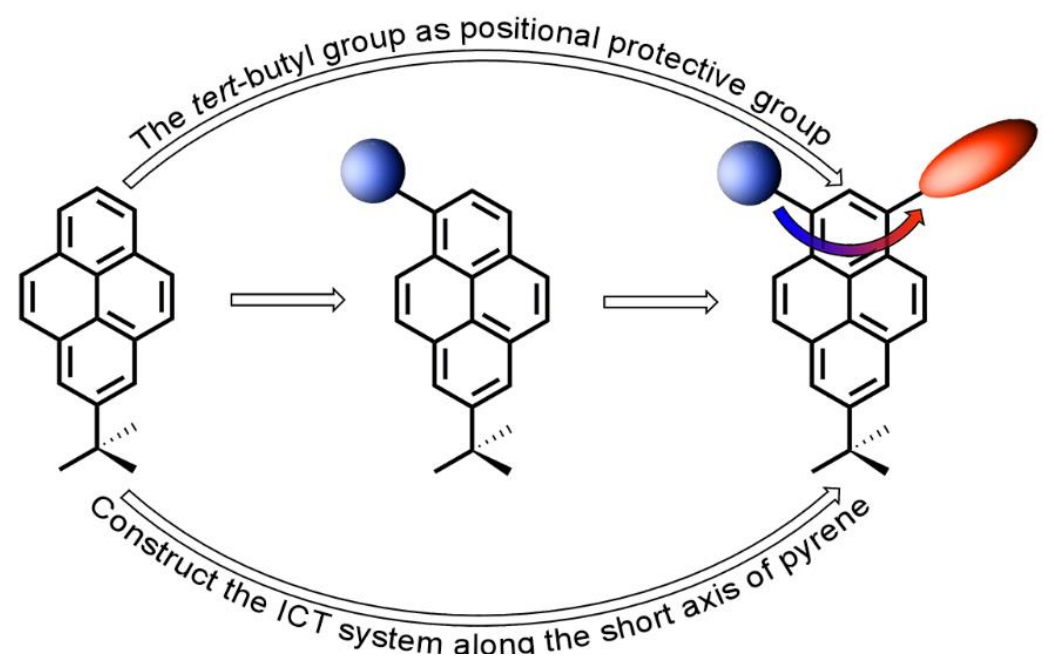




\title{
Tetrahedron
}

\section{Short axially asymmetrically 1,3 -disubstituted pyrene-based color-tunable emitters: Synthesis, characterization and optical properties}

\author{
Chuan-Zeng Wang ${ }^{a, b}$, Zi-Jin Pang $^{a}$, Ze-Dong Yu ${ }^{a}$, Zhao-Xuan Zeng ${ }^{a}$, Wen-Xuan Zhao ${ }^{a}$, Zi-Yan Zhou, $^{* a}$ \\ Carl Redshaw ${ }^{c}$, Takehiko Yamato ${ }^{b, *}$ \\ ${ }^{a}$ School of Chemical Engineering, Shandong University of Technology, Zibo 255049, P. R. China, E-mail: zyzhou@sdut.edu.cn \\ ${ }^{b}$ Department of Applied Chemistry, Faculty of Science and Engineering, Saga University, Honjo-machi 1, Saga, 840-8502 Japan, E-mail: \\ yamatot@cc.saga-u.ac.jp \\ Department of Chemistry, The University of Hull, Cottingham Road, Hull, Yorkshire, HU6 7RX, UK
}

\section{ARTICLE INFO}

ABSTRACT

Article history:

Received

Received in revised form

Accepted

Available online

In contrast to conventional pyrene-based emitters which feature $\mathrm{D}-\pi$-A type structures, a new class of emitters possessing a short axis are gaining constant interest owing to both their academic importance and promising applications in organic optoelectronic materials. Herein, donor and acceptor substituents were introduced at 1-, 3-positions by employing a two step of bromination reaction which enabled first prepared according to the non-statistic. Two 1donor-3-acceptor pyrenes were systematically investigated by ${ }^{1} \mathrm{H} /{ }^{13} \mathrm{C}$ NMR spectroscopy, optical spectroscopy, and theoretical calculations. The preliminary research of the substituent positions and substitutions pattern on the properties of the materials as well as on the frontier orbitals is reported. And the experimental results indicated that the strong impact on the photophysical properties endowed with the possibility of precise color-control of pyrene derivatives through substituent variation.

2019 Elsevier Ltd. All rights reserved.

\section{Introduction}

In recent years, the functionalization of pyrene has inspired numerous researchers due to its unique properties in the material arena. ${ }^{1-3}$ The synthesis of asymmetric derivatives is one of the most popular topics and typically involves the design of donor-acceptor (D-A) type molecules. Such species shows great adjustability for optoelectronic properties because of their efficient excited-state intramolecular charge transfer (ICT). ${ }^{4-6}$ It is known that long axial asymmetrically pyrene-based derivatives functionalized at the 1-, 3-, 6-, 8-positions can be accessed by an electrophilic substitution reaction due to the HOMOs have largest coefficients, and such species possess outstanding properties. $^{7-10}$ Moreover, $1,6-$ or $1,8-$ disubstituted and 1,3,6,8-tetrasubstituted asymmetric pyrene-based materials appending two or two pairs different groups have been reported with excellent photoelectric properties. ${ }^{1,2}$ However, high chemical activity has led to many challenges such as the formation of numerous isomers that are very difficult to separate. ${ }^{11}$

\footnotetext{
Corresponding author. Fax: +81 95228 8548; e-mail address: yamatot@cc.saga-u.ac.jp
} (T. Yamato)
Interestingly, 2,7-disubstituted pyrene derivatives exhibited distinct difference in their optical behaviour, such as single molecular white emitters, ${ }^{12}$ adjustable redox potentials and frontier orbitals. ${ }^{13-15}$ Recently, a controllable regioselective approach at alternative positions was established by Yamato and co-workers, ${ }^{16}$ which achieved the stepwise functionalization at the K-region (5-, 9-positions) and the active sites (1-, 3-positions). The strategy expands the scope of pyrene-based photoelectric materials. Meanwhile, there has been some significant work based on functionalization along the short axis. Müllen and coworkers opened up new method to functionalize pyrene at the K-region via bromination and presented a few examples possessing long wave emission (> $600 \mathrm{~nm}) .{ }^{17,18}$ There are also a number of reports concerning $D-\pi$-A type pyrenes, such as those obtained by combining 2,7- or 1,8-acceptor moieties with 4,5- donor moieties which led to strongly redshifted absorptions with high molar absorptivities, ${ }^{19-21}$ and a series of green and blue emitters prepared by introducing donor and acceptor groups at the 1,8-positions and 3,6positions, respectively. ${ }^{22,23}$ On the basis of these studies, the possibility of position-dependent photoelectric properties 
inspired our interest to construct $D-\pi$-A type pyrene systems in less explored positional regions.
1

2

3

4

5

6

7

8

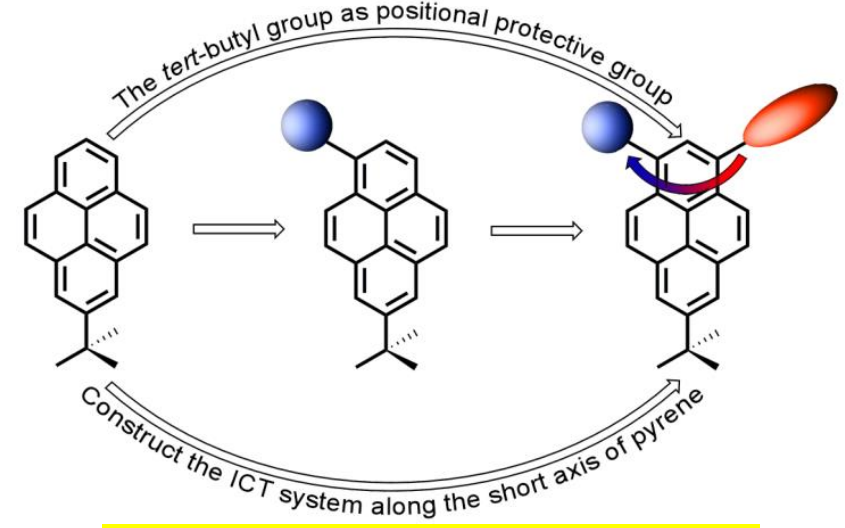

Scheme 1. Illustration of the pyrene-based D- $\pi$-A emitters.

In our previous report, we presented a facile and predictive strategy to tune the emission color by constructing $\mathrm{D}-\pi$-D pyrenes at the $1-, 3$-positions. ${ }^{24}$ Taking account of the above considerations, two 1-donor-3-acceptor pyrenes with tuneable highest occupied molecular orbital (HOMO) and lowest unoccupied molecular orbital (LUMO) levels are presented (Scheme 1). New pyrene chemistry has therefore been developed for the stepwise functionalization at the 1-, 3-positions starting from 7-tert-butylpyrene.

\section{Results and discussion}

\subsection{Synthesis and characterization}

In general, the electrophilic substitution reaction shows high activity at the 1-, 3-, 6-, and 8-positions of pyrene. Thus, various pyrene derivatives ${ }^{1}$ can be easily accessed depending on the experimental conditions. However, it is quite difficult to introduce different substituents selectively at the 1 - and 3-positions of pyrene by direct electrophilic aromatic substitution reactions due to the formation of 1,6and 1,8-substituted products. According to previous reports, 7-tert-butyl-1,3-dibromopyrene $3^{25,26}$ can be synthesized from 2-tert-butylpyrene 1 with $\mathrm{Br}_{2}$ at temperatures below $78^{\circ} \mathrm{C}$ based on positional protective strategy by employing a tert-butyl group. However, the sensitivity to experimental conditions leads to the formation of complex by-products, which also limits the synthesis of this kind of compounds to some extent. Previously, we reported that treatment of 2tert-butylpyrene $\mathbf{1}$ with benzyltrimethylammonium tribromide (BTMABr 3 ) (3.5 equiv.) in dry $\mathrm{CH}_{2} \mathrm{Cl}_{2}$ at room temperature to give the desired 1,3-dibromo-7-tertbutylpyrene $\mathbf{3}$ in good yield $(76 \%)$. And a mixture of $\mathbf{1}$ and $\mathrm{BTMABr}_{3}$ (1.1 equiv.) in $\mathrm{CH}_{2} \mathrm{Cl}_{2}$ at room temperature for 12 $\mathrm{h}$ afforded the desired product 2 in $84 \%$ yield along with recovery of the starting compound $\mathbf{1}$ and 1,3-dibromo-7-tertbutylpyrene 3 . $^{27,28}$ On the other hand, bromination of $\mathbf{1}$ was performed with $\mathrm{N}$-bromosuccinimide (NBS) (1.1 equiv.) in $\mathrm{THF}$ at room temperature for $12 \mathrm{~h}$, which exclusively afforded 2 in $94 \%$ yield. The 7-tert-butyl-1-arylpyrenes 4 arylboronic acid by the Suzuki-Miyaura cross-coupling reaction in good yields. Bromination of $\mathbf{4 a}$ and $\mathbf{4 b}$ with $\mathrm{BTMABr}_{3}$ (1.5 equiv.) in $\mathrm{CH}_{2} \mathrm{Cl}_{2}-\mathrm{MeOH}$ at room temperature for $6 \mathrm{~h}$ occurred selectively at 3-position to afford the desired 1-aryl-3-bromopyrene $\mathbf{5 a}$ and $\mathbf{5 b}$ in 88 and $98 \%$ yields, respectively. The target 1,3-asymmetrically substituted pyrenes $\mathbf{6}$ were synthesize from 5 by Sonogashira coupling reactions with the corresponding arylacetylenes as shown in Scheme 2. In particular, a new method to introduce the functional groups at the terminal of pyrene is presented, and the key step of this novel strategy is the bromination reaction at 1- and 3-positions by employing benzyltrimethylammonium tribromide (BTMABr 3$)$ and NBS under moderate conditions. All products and intermediates were fully characterized by high-resolution mass spectrometry and NMR spectroscopy (see Figs. S2-10 in the Supporting information). The thermal stabilities of $\mathbf{6}$ were researched by thermogravimetric analysis (TGA) at a heating rate of $10^{\circ} \mathrm{C} \mathrm{min}^{-1}$ under a nitrogen atmosphere (Fig. $\mathrm{S} 11)$. The results showed that emitters 6 exhibited high thermal stabilities $\left(\mathrm{Td}>400{ }^{\circ} \mathrm{C}\right)$, which also suggest great potential application in organic electronics materials. were synthesized from bromide $\mathbf{2}$ with the corresponding
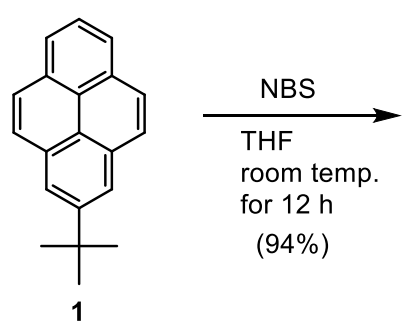<smiles>CC(C)(C)C1=c2c3c(Br)ccc2=CC=C2CCC(=C1)C2=C3</smiles>

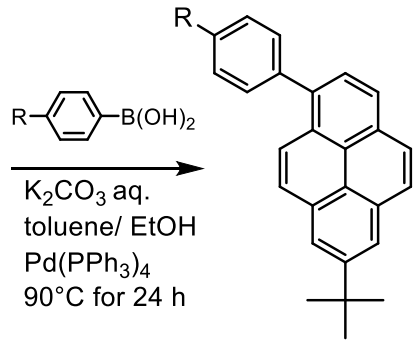

4a: $\mathrm{R}=\mathrm{H}(76 \%)$ 4b: $\mathrm{R}=\mathrm{CHO}(53 \%)$

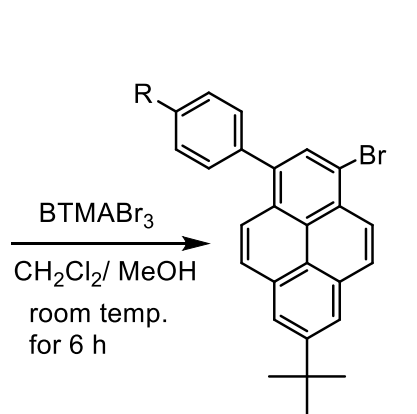<smiles>[R]c1ccc(-c2cc(C#Cc3ccc(N(C)C)cc3)c3ccc4cc(C(C)(C)C)cc5ccc2c3c45)cc1</smiles>

5a: $\mathrm{R}=\mathrm{H}(88 \%)$ 5b: $\mathrm{R}=\mathrm{CHO}(98 \%)$ 6a: $\mathrm{R}=\mathrm{H}(50 \%)$

6b: $\mathrm{R}=\mathrm{CHO}(39 \%)$ 
Scheme 2. Synthetic route to emitters 6.

\subsection{Photophysical properties}

1
Detailed studies of their photophysical properties were performed by comparing with the reference compound of 1,3-diphenyl-7-tert-butylpyrene 7. ${ }^{26}$ As shown in Fig. 1 left and Table 1, the absorption spectra of $\mathbf{6}$ in $\mathrm{CH}_{2} \mathrm{Cl}_{2}$ (DCM) solution exhibit a set of obvious absorption bands at around 270-340 nm with a shoulder band observed at around 400 $\mathrm{nm}$. By comparing the spectrum of reference compound 7 given in Table 1, the absorption bands at short wavelengths benefit from the bathochromic shift of the absorption of the phenyl and pyrene core, which can be ascribed to the intramolecular $\pi-\pi^{*}$ transition of the extended $\pi$-conjugation of alkynyl and phenyl groups, while the low-energy shoulder absorption with high molar absorption coefficients indicates that their excited states possess significant charge transfer absorption associated with the intramolecular charge transfer from the arylethynyl units to the aryl group via the pyrene core. Meanwhile, slightly difference of the shoulder at 400 $\mathrm{nm}$ and obvious difference at around $350 \mathrm{~nm}$ indicated that the strength and region of charge transfer play a significant role for the absorption properties. This indicates that a more efficient excited-state intramolecular charge transfer has occurred in this type of pyrene derivatives.

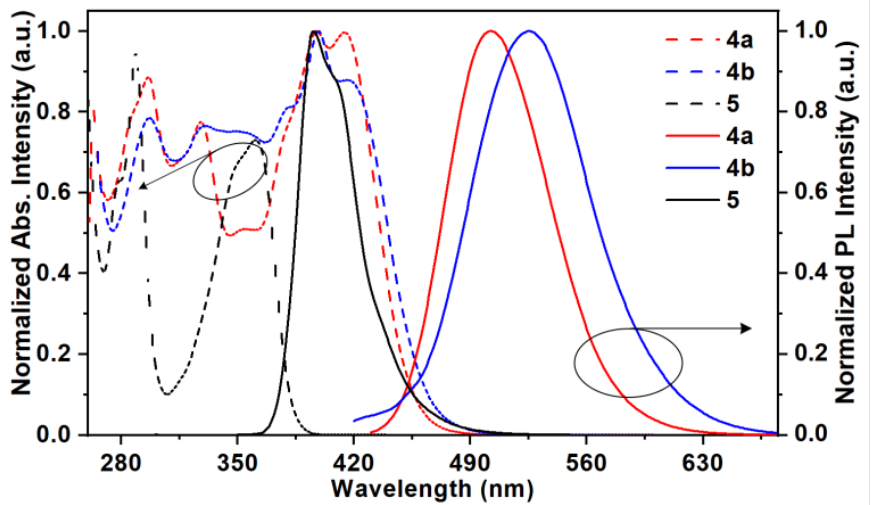

Figure 1. UV-Vis absorption spectra (left arrow) and fluorescence spectra (right arrow) of $\mathbf{6 a}, \mathbf{6 b}$ and 7 in DCM solutions at $\sim 10^{-5}-10^{-7} \mathrm{M}$ at room temperature.

Table 1. Optical absorption and emission spectroscopic data of compounds $6 \mathbf{6}, \mathbf{6 b}$ and 7. ${ }^{[a]}$

\begin{tabular}{|c|c|c|c|c|c|c|c|}
\hline Compounds & $\lambda_{\max } \operatorname{abs}[\mathrm{nm}]^{[\mathrm{b}]}$ & $\lambda_{\max } \mathrm{PL}[\mathrm{nm}]^{[\mathrm{c}]}$ & Stokes-shift [nm] & $\begin{array}{c}\text { HOMO } \\
(\mathrm{eV})\end{array}$ & $\begin{array}{c}\text { LUMO } \\
(\mathrm{eV})\end{array}$ & $\begin{array}{l}\Delta \mathrm{E}^{[\mathrm{d}]} \\
(\mathrm{eV})\end{array}$ & $\Phi_{F}^{[\mathrm{e}]}$ \\
\hline $6 \mathbf{a}$ & 396 & 502 & 106 & -4.56 & -1.60 & 3.05 & 0.88 \\
\hline $6 \mathbf{b}$ & 398 & 525 & 137 & -4.76 & -1.90 & 2.86 & 0.07 \\
\hline 7 & 360 & 396 & 36 & -5.09 & -1.55 & 3.54 & 0.38 \\
\hline
\end{tabular}

${ }^{a}$ All measurements were performed under degassed conditions. ${ }^{\mathrm{b}} \sim \times 10^{-5} \mathrm{M}^{\text {in }} \mathrm{CH}_{2} \mathrm{Cl}_{2}, \lambda_{\text {abs }}$ is the absorption band appearing at the longest wavelength. ${ }^{c} \sim \times 10^{-7} \mathrm{M}$ in $\mathrm{CH}_{2} \mathrm{Cl}_{2}, \lambda_{\text {ex }}$ is the fluorescence band appearing at the shortest wavelength. ${ }^{\mathrm{d}}$ DFT/B3LYP/6-31G* using Gaussian. ${ }^{\mathrm{e}}$ Absolute quantum yield $( \pm 0.01-0.03)$ in dichloromethane.

On the other hand, the emission spectra of emitters 6 present a simple and clear emission band. More specifically, the emission maxima are in the range $502-525 \mathrm{~nm}$ in dilute DCM solution with an obvious red-shift (more than $100 \mathrm{~nm}$ ) compared with compound 7 (396 nm) (Fig. 1 right). Compounds $6 \mathbf{a}$ and $\mathbf{6 b}$ exhibit green emission with peaks at $502 \mathrm{~nm}$ and $525 \mathrm{~nm}$, respectively. The photoluminescence quantum yields of emitters 6 were also recorded, and two compounds exhibit reasonable quantum yields $\left(\Phi_{\mathrm{F}}\right)$, especially for $\mathbf{6 a}$, the $\Phi_{\mathrm{F}}$ in DCM solution up to $88 \%$, showing a substantial enhancement compared to $7\left(\Phi_{\mathrm{F}}=\right.$ $38 \%$ ), which benefit from the expended $\pi$ conjugated system. On the other hand, the $\Phi_{\mathrm{F}}$ value of $\mathbf{6} \mathbf{b}$ shows increasing trend due to the influence of distinct intramolecular charge transfer. As expected, based on our novel design strategy of short axially asymmetrically 1-donor-3-acceptor pyrenes, two compounds exhibit efficient color-tunable properties.

In order to investigate the emission mechanism of these two short axially D- $\pi$-A type pyrene emitters, solvatochromism was carried out in solvents of different polarities (dimethyl formamide (DMF), tetrahydrofuran (THF), dichloromethane (DCM), 1,4-dioxane, and cyclohexane). Pertinent data for the absorption and emission spectra are shown in Fig. 2 and Figs. S12-17). The absorption spectra of compounds of type $\mathbf{6}$ all present zero or minimum solvent dependence. In sharp contrast, significant solvatochromism was observed for the emission spectra of both emitters. Both two compounds $\mathbf{6 a}-\mathbf{b}$ exhibited significant bathochromic shift for their emission spectra in different solution, as large as $116 \mathrm{~nm}$, and $95 \mathrm{~nm}$ for $6 \mathbf{a}$, and $\mathbf{6 b}$, respectively. Based on the case study of $\mathbf{6 a}$, as depicted in Fig. 2b, which exhibited significant color change from sky-blue to yellow from cyclohexane solution to DMF solution. The results further indicate that emitters 6 are tuneable and favorable luminescent materials. Meanwhile, this result of solvatochromism was further elucidated by the relationship between the Lippert equation and the Stokes shifts in various solvents. ${ }^{29,30}$ The LippertMataga plots present linear correlation together with a high slope value, which indicate that the dipolar moment of the intramolecular excited state is larger than the ground state because of the substantial charge redistribution. And the value of the slope for $\mathbf{6 a}$ (12802), and $\mathbf{6 b}$ (10529) is far larger than that for 7 (-200). Moreover, compared with the other D- $\pi$-A systems, the slope of the fitting lines for this project are larger than most reported results, ${ }^{6,31}$ which is mainly depended on their dissimilar intramolecular charge transfer effectiveness and pathways of the 1-donor-3acceptor pyrene system. The other crucial factor, the twisted intramolecular charge transfer (TICT), might also play an important role in solution state due to the 4-N,Ndimethylaminophenyl moiety. ${ }^{32}$ As a control, comparing 
with other reported asymmetrically pyrene derivatives with

1

2

3

4

5

6

7

8

9

10

11

12

13

14

15

16

17

18

19

20

21

22

23

24

25

26 phenyl groups and aryne groups, ${ }^{16,33}$ high tunability and more distinct charge separations were observed by

Figure 3. HOMO/LUMO energy levels and frontier molecular orbitals obtained from DFT calculations on $\mathbf{6 a}, \mathbf{6 b}$ and 7 with optimized geometries. $\Delta E$ is an energy bandgap of these three compounds estimated from difference between the HOMO and LUMO values.

\section{Conclusion}

In summary, two novel D- $\pi$-A emitters were prepared by a stepwise bromination reaction, a Suzuki-Miyaura crosscoupling reaction, and a Sonogashira coupling reaction in reasonable yield. Depending on the electronwithdrawing/donating groups along the short axis, the theoretical and experimental results of $\mathbf{6}$ exhibited an obvious adjustability of color and other properties. Two compounds exhibit high thermal stability and good solubility. The present work not only opens up new avenues to explore a novel functionalization strategy and to broaden the scope for constructing efficient pyrene-based optoelectronic materials. Ongoing works are focusing on this type of emitter and will be published soon.

To investigate the orbital energies, electron densities, electronic structures of the highest occupied molecular orbital (HOMO) and lowest unoccupied molecular orbital (LUMO) states of the compounds $\mathbf{6}$ and $\mathbf{7}$, as well as to elucidate the photophysical characteristics, density functional theory (DFT) calculations were carried out on the two compounds at the B3LYP/6-31G* level. In general, acceptor groups have an effect on the LUMOs because they are prone to accept electrons, donor groups on the other hand can provide a significant contribution to the HOMOs because they are prone to donate electrons. ${ }^{34}$ For this kind of donor- $\pi$-acceptor (D- $\pi$-A) structures, the energy gaps of these new emitters can be significantly tuned compared with the naked components. As depicted in Fig. 3, the significant difference of distribution of LUMOs and HOMOs of emitters 6 result from the presence of the strong electrondonating nature of the $N, N$-dimethylaminophenyl group,,$^{33}$ and especially for compound $\mathbf{6 b}$, the efficient electronwithdrawing nature of the formyl group provided energetically enhanced LUMOs, which are mainly distributed over the pyrene core and 4-formylphenyl substituents. These results of theoretical calculations indicating the emitters 6 allow them to exhibit enhanced ICT character compared with $\mathbf{7}$, the fluorescent behaviour is sensitive to structural change, which impacts on the distribution of the LUMOs and HOMOs, particularly polarity, ${ }^{35}$ which is consistent with the experimental results, such as emission spectra, solvatochromism.
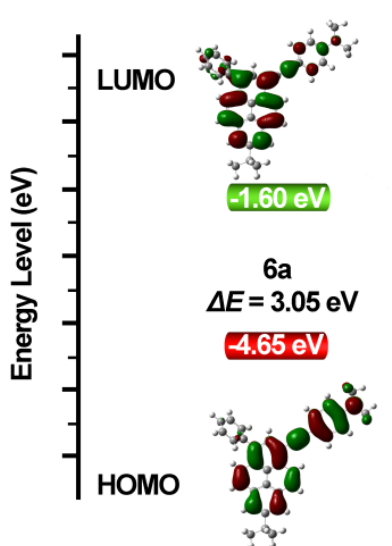

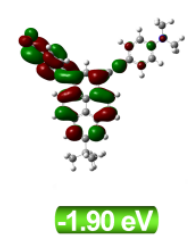

$6 \mathrm{~b}$
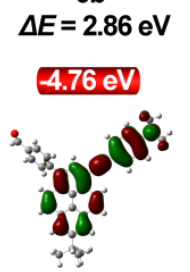

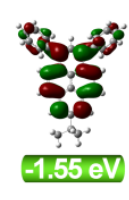

7 $\Delta E=3.54 \mathrm{eV}$ $-5.09 \mathrm{eV}$

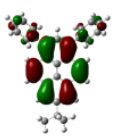

\section{Experimental section}

All melting points are uncorrected. All reactions were performed under a dry $\mathrm{N}_{2}$ atmosphere. Solvents were Guaranteed reagent (GR) for dimethylformamide (DMF), tetrahydrofuran (THF), dichloromethane (DCM), 1,4dioxane, and cyclohexane, and stored over molecular sieves. Other reagents were obtained commercially and used without further purification. Reactions were monitored using thin layer chromatography (TLC). Commercial TLC plates (Merck Co.) were developed and the spots were identified under UV light at 254 and $365 \mathrm{~nm}$. Column chromatography was performed on silica gel $60(0.063-0.200 \mathrm{~mm})$. All synthesized compounds were characterized using ${ }^{1} \mathrm{H} /{ }^{13} \mathrm{C}$ NMR spectroscopy, and by HRMS (FAB) mass analysis. Fluorescence spectroscopic studies were performed in various organic solvents in a semimicro fluorescence cell (Hellma®, 104F-QS, $10 \times 4 \mathrm{~mm}, 1400 \mu \mathrm{L}$ ) with a Varian Cary Eclipse spectrophotometer. Fluorescence quantum yields were measured using absolute methods.

\subsection{General procedure for the systhesis of 2}

$N$-Bromosucccinimide (NBS) (195.8 mg, $1.1 \mathrm{mmol}$ ) was slowly added to a solution of 2-tert-butylpyrene $\mathbf{1}(258 \mathrm{mg}, 1 \mathrm{mmol})$ in dry tetrahydrofuran $(10 \mathrm{~mL})$ at $0{ }^{\circ} \mathrm{C}$ under a nitrogen atmosphere. The resulting mixture was allowed to slowly warm up to room temperature and stirred overnight. The reaction mixture was quenched with $\mathrm{Na}_{2} \mathrm{~S}_{2} \mathrm{O}_{3}$ and extracted with $\mathrm{CH}_{2} \mathrm{Cl}_{2}(2 \times 20 \mathrm{~mL})$. The combined organic extracts were dried with anhydrous $\mathrm{MgSO}_{4}$ and evaporated. The residue was crystallized from hexane to give pure 1-bromo-7-tert-butylpyrene $\mathbf{2}$ in as white crystals (318 mg, 94\%). The ${ }^{1} \mathrm{H}$ NMR spectrum completely agreed with the reported values. ${ }^{27}$

\subsection{The Suzuki-Miyaura coupling reaction towards the synthesis of $4 \boldsymbol{a}-\boldsymbol{b}$}

A mixture of 1-bromo-7-tert-butylpyrene 2 (675 mg, 2.0 $\mathrm{mmol})$, ethanol $(10 \mathrm{~mL})$ and arylboronic acid $(4.0 \mathrm{mmol})$ in toluene $(40 \mathrm{~mL})$ and at room temperature was stirred under argon, and $\mathrm{Pd}\left(\mathrm{PPh}_{3}\right)_{4}(35 \mathrm{mg}, 1.5 \mathrm{~mol} \%)$ and a $2 \mathrm{M}$ aqueous 
solution of $\mathrm{Na}_{2} \mathrm{CO}_{3}(40 \mathrm{~mL})$ were added. After the mixture was stirred for $30 \mathrm{~min}$ under argon at room temperature, the mixture was heated to $90{ }^{\circ} \mathrm{C}$ with stirring for $24 \mathrm{~h}$. The mixture was cooled to room temperature, and the mixture was quenched with water, extracted with $\mathrm{CH}_{2} \mathrm{Cl}_{2}(2 \times 100$ $\mathrm{mL}$ ), and washed with water and brine. The organic extracts were dried with $\mathrm{MgSO}_{4}$ powder and the solvent was evaporated. The crude reaction mixture, which was further describe as indicated in the individual cases

\subsection{Synthesis of 7-tert-butyl-1-phenylpyrene (4a)}

A similar procedure with phenylboronic acid $(488 \mathrm{mg}, 4.0$ mmol), was followed for the synthesis of $\mathbf{4 a} .^{36} \mathbf{4 a}$ was obtained as white solid (recrystallized from hexane- $\mathrm{CHCl}_{3}$ (9:1); $510 \mathrm{mg}, 76 \%) .{ }^{1} \mathrm{H} \mathrm{NMR}\left(400 \mathrm{MHz}, \mathrm{CDCl}_{3}\right) \delta(\mathrm{ppm})=$ $1.58(\mathrm{~s}, 9 \mathrm{H}, t \mathrm{Bu}), 7.48(\mathrm{~m}, 1 \mathrm{H}, \operatorname{Ar}-H), 7.56(\mathrm{t}, J=7.4,2 \mathrm{H}$, $\operatorname{Ar}-H), 7.64(\mathrm{~d}, J=7.7 \mathrm{~Hz}, 2 \mathrm{H}, \operatorname{Ar}-H), 7.94(\mathrm{~d}, J=7.8 \mathrm{~Hz}$, $1 \mathrm{H}$, pyrene- $H), 8.00(\mathrm{~d}, J=9.3 \mathrm{~Hz}, 1 \mathrm{H}$, pyrene- $H), 8.07(\mathrm{~d}$, $J=1.5 \mathrm{~Hz}, 2 \mathrm{H}$, pyrene- $H), 8.14(\mathrm{~d}, J=9.3 \mathrm{~Hz}, 1 \mathrm{H}$, pyrene$H), 8.18(\mathrm{~d}, J=8.0 \mathrm{~Hz}, 1 \mathrm{H}$, pyrene- $H), 8.21(\mathrm{~d}, J=9.3 \mathrm{~Hz}$, $1 \mathrm{H}$, pyrene- $H$ ), 8.22 (d, $J=9.3 \mathrm{~Hz}, 1 \mathrm{H}$, pyrene- $H$ ).

\subsection{Synthesis of 7-tert-butyl-1-(4-formylphenyl)pyrene (4b)}

A similar procedure with 4-formylphenylboronic acid $(600 \mathrm{mg}$, $4.0 \mathrm{mmol}$ ), was followed for the synthesis of $\mathbf{4 b}$. $\mathbf{4 b}$ was obtained as yellow solid (recrystallized from hexane- $\mathrm{CHCl}_{3}(6: 1) ; 379$ mg, 53\%). M.p. $134-136{ }^{\circ} \mathrm{C} ;{ }^{1} \mathrm{H}$ NMR $\left(400 \mathrm{MHz}, \mathrm{CDCl}_{3}\right) \delta$ $(\mathrm{ppm})=1.59(\mathrm{~s}, 9 \mathrm{H}, t \mathrm{Bu}), 7.83(\mathrm{~d}, J=8.0 \mathrm{~Hz}, 2 \mathrm{H}$, Ar- $H), 7.94$ $(\mathrm{d}, J=7.8 \mathrm{~Hz}, 2 \mathrm{H}, \mathrm{Ar}-H), 8.04$ (d, $J=9.3 \mathrm{~Hz}, 1 \mathrm{H}, \mathrm{Ar}-H), 8.06$ $8.12(\mathrm{~m}, 5 \mathrm{H}$, pyrene- $H), 8.19-8.25(\mathrm{~m}, 2 \mathrm{H}$, pyrene- $H), 10.16(\mathrm{~s}$, $1 \mathrm{H}, \mathrm{CHO}), \mathrm{FAB}-\mathrm{MS}: \mathrm{m} / \mathrm{z}$ calcd for $\mathrm{C}_{27} \mathrm{H}_{22} \mathrm{O} 362.1671\left[\mathrm{M}^{+}\right]$; found $362.1670\left[\mathrm{M}^{+}\right]$

\subsection{Synthesis of 7-tert-butyl-1-phenyl-3-bromopyrene (5a)}

A Compound 7-tert-butyl-1-phenylpyrene 4a (334 mg, 1.0 mmol) was added in $\mathrm{CH}_{2} \mathrm{Cl}_{2}(9 \mathrm{~mL})$ and $\mathrm{MeOH}(25 \mathrm{~mL})$, and the mixture was stirred under argon atmosphere at $0{ }^{\circ} \mathrm{C}$. After 30 min, $\mathrm{BTMABr}_{3}(585 \mathrm{mg}, 1.5 \mathrm{mmol})$ was added. The resulting mixture was stirred for $6 \mathrm{~h}$ at room temperature under argon. The mixture was extracted with $\mathrm{CH}_{2} \mathrm{Cl}_{2}(2 \times 50 \mathrm{~mL})$, and the combined extracts were washed with water and brine, dried with $\mathrm{MgSO}_{4}$ powder and concentrated. The residue was chromatographed over silica gel (Wako C-300, $200 \mathrm{~g}$ ) with hexane- $\mathrm{CHCl}_{3}(9: 1)$ as eluent to give a white solid (366 mg, 88\%). M.p. $110-112{ }^{\circ} \mathrm{C} ;{ }^{1} \mathrm{H}$ NMR $\left(400 \mathrm{MHz}, \mathrm{CDCl}_{3}\right) \delta(\mathrm{ppm})=$ $1.59(\mathrm{~s}, 9 \mathrm{H}, t \mathrm{Bu}), 7.47-7.62(\mathrm{~m}, 5 \mathrm{H}, \operatorname{Ar}-H), 7.94(\mathrm{~d}, J=8.0 \mathrm{~Hz}$, $1 \mathrm{H}$, pyrene- $H), 8.01(\mathrm{~d}, J=9.2 \mathrm{~Hz}, 1 \mathrm{H}$, pyrene- $H), 8.08(\mathrm{~d}, J=$ $9.3 \mathrm{~Hz}, 1 \mathrm{H}$, pyrene- $H$ ), $8.17(\mathrm{~d}, J=9.2 \mathrm{~Hz}, 1 \mathrm{H}$, pyrene- $H$ ), $8.20-8.24(\mathrm{~m}, 2 \mathrm{H}$, pyrene- $H), 8.27(\mathrm{~s}, 1 \mathrm{H}$, pyrene- $H), 8.43(\mathrm{~d}, J$ $=9.2,1 \mathrm{H}$, pyrene- $H$ ). FAB-MS: $m / z$ calcd for $\mathrm{C}_{26} \mathrm{H}_{21} \mathrm{Br} 412.0827$ $\left[\mathrm{M}^{+}\right]$; found $412.0827\left[\mathrm{M}^{+}\right]$.

\subsection{Synthesis of 7-tert-butyl-1-(4-formylphenyl)-3-bromopyrene} $(5 b)$

A Compound 7-tert-butyl-1-(4-formylphenyl)pyrene $\mathbf{4 b}$ (200 mg, $0.56 \mathrm{mmol})$ was added in $\mathrm{CH}_{2} \mathrm{Cl}_{2}(5 \mathrm{~mL}), \mathrm{MeOH}(15 \mathrm{~mL})$, and the mixture was stirred under argon atmosphere at $0{ }^{\circ} \mathrm{C}$. After 30 min, $\mathrm{BTMABr}_{3}(328 \mathrm{mg}, 0.84 \mathrm{mmol})$ was added. The resulting mixture was stirred for $6 \mathrm{~h}$ at room temperature under argon. The mixture was extracted with $\mathrm{CH}_{2} \mathrm{Cl}_{2}(2 \times 30 \mathrm{~mL})$, and the combined extracts were washed with water and brine, dried with $\mathrm{MgSO}_{4}$ powder and concentrated. The residue was chromatographed over silica gel (Wako C-300, $150 \mathrm{~g}$ ) with hexane- $\mathrm{CHCl}_{3}(7: 1)$ as eluent to give a pale-yellow solid (240 mg, 98\%). M.p. ${ }^{122-124}{ }^{\circ} \mathrm{C} ;{ }^{1} \mathrm{H}$ NMR (400 MHz, $\left.\mathrm{CDCl}_{3}\right) \delta$ $(\mathrm{ppm})=1.52(\mathrm{~s}, 9 \mathrm{H}, t \mathrm{Bu}), 7.73(\mathrm{~d}, J=7.7 \mathrm{~Hz}, 2 \mathrm{H}$, Ar- $H), 7.97$ $(\mathrm{d}, J=7.7 \mathrm{~Hz}, 2 \mathrm{H}, \operatorname{Ar}-H), 8.02(\mathrm{~d}, J=7.9 \mathrm{~Hz}, 2 \mathrm{H}$, pyrene- $H$ ), $8.15(\mathrm{~d}, J=7.9 \mathrm{~Hz}, 2 \mathrm{H}$, pyrene- $H), 8.19$ (s, $1 \mathrm{H}$, pyrene- $H), 8.24$ (s, $1 \mathrm{H}), 8.38(\mathrm{~d}, J=9.3 \mathrm{~Hz}, 1 \mathrm{H}$, pyrene- $H), 10.10(\mathrm{~s}, 1 \mathrm{H}, \mathrm{CHO})$. ${ }^{13} \mathrm{C}$ NMR $\left(100 \mathrm{MHz}, \mathrm{CDCl}_{3}\right) \delta(\mathrm{ppm})=192.13,150.26,146.45$, $136.65,135.57,131.36,131.25,130.98,130.82$, 130.03, 129.82, $129.55,128.65,127.84,126.25,125.89,124.42,123.54,123.40$, 122.56, 119.62, 35.43, 32.00. FAB-MS: $m / z$ calcd for $\mathrm{C}_{27} \mathrm{H}_{21} \mathrm{BrO}$ $440.0776\left[\mathrm{M}^{+}\right]$; found $440.0775\left[\mathrm{M}^{+}\right]$.

\subsection{Synthesis of 7-tert-butyl-1-phenyl-3-(4-N,N- dimetylaminophenylethynyl)pyrene $(\boldsymbol{6 a})$}

A mixture of 7-tert-butyl-1-phenyl-3-bromopyrene 5a (150 mg, $0.36 \mathrm{mmol}), \mathrm{N}, \mathrm{N}$-dimetylaminophenyl acetylene $(105 \mathrm{mg}, 0.73$ $\mathrm{mmol}), \mathrm{PPh}_{3}$ (9 mg, $\left.0.036 \mathrm{mmol}\right), \mathrm{CuI}(7 \mathrm{mg}, 0.36 \mathrm{mmol})$, $\mathrm{PdCl}_{2}\left(\mathrm{PPh}_{3}\right)_{3}(13 \mathrm{mg}, 0.036 \mathrm{mmol})$ were added to a degassed solution of DMF $(8 \mathrm{~mL})$ and $\mathrm{Et}_{3} \mathrm{~N}(8 \mathrm{~mL})$. The resulting mixture was stirred at $100{ }^{\circ} \mathrm{C}$ for $24 \mathrm{~h}$. After it was cooled to room temperature, the reaction was quenched with water. The mixture was extracted with $\mathrm{CH}_{2} \mathrm{Cl}_{2}(2 \times 50 \mathrm{~mL})$, the organic layer was washed with water $(2 \times 30 \mathrm{~mL})$ and brine $(30 \mathrm{~mL})$, and then the solution was dried $\left(\mathrm{MgSO}_{4}\right)$, and evaporated. The residue was purified by column chromatography eluting with a hexane$\mathrm{CHCl}_{3}$ (3:2) mixture to give $\mathbf{6 a}$ as a yellow crystalline powder (86.1 mg, 50\%). M.p. 206-208 ${ }^{\circ} \mathrm{C} ;{ }^{1} \mathrm{H}$ NMR (400 MHz, $\left.\mathrm{CDCl}_{3}\right) \delta$ $(\mathrm{ppm})=1.59(\mathrm{~s}, 9 \mathrm{H}, t \mathrm{Bu}), 3.03\left(\mathrm{~s}, 6 \mathrm{H}, \mathrm{NMe} e_{2}\right), 6.74(\mathrm{~d}, J=7.2$ $\mathrm{Hz}, 2 \mathrm{H}, \mathrm{Ar}-H), 7.49$ (d, $J=7.0 \mathrm{~Hz}, 1 \mathrm{H}, \mathrm{Ar}-H), 7.54-7.62(\mathrm{~m}, 4 \mathrm{H}$, Ar- $H$ ), $7.65(\mathrm{~d}, J=7.1 \mathrm{~Hz}, 2 \mathrm{H}, \operatorname{Ar}-H), 7.99(\mathrm{~d}, J=9.0 \mathrm{~Hz}, 1 \mathrm{H}$, pyrene- $H), 8.10(\mathrm{~d}, J=8.8 \mathrm{~Hz}, 1 \mathrm{H}$, pyrene- $H), 8.17(\mathrm{~m}, 3 \mathrm{H}$, pyrene- $H$ ), $8.25(\mathrm{~s}, 1 \mathrm{H}$, pyrene- $H), 8.68(\mathrm{~d}, J=8.9 \mathrm{~Hz}, 1 \mathrm{H}$, pyrene- $H) .{ }^{13} \mathrm{C}$ NMR $\left(100 \mathrm{MHz}, \mathrm{CDCl}_{3}\right) \delta(\mathrm{ppm})=149.50$, $140.86,137.33$, 133.00, 131.50, 131.15, 130.81, 130.67, 128.49, 128.27, 128.06, 127.45, 125.83, 125.22, 122.91, 122.59, 118.49, 112.05, 96.57, 87.72, 40.44, 35.36, 32.04. FAB-MS: $\mathrm{m} / \mathrm{z}$ calcd for $\mathrm{C}_{36} \mathrm{H}_{31} \mathrm{~N} 477.2457\left[\mathrm{M}^{+}\right]$; found $477.2454\left[\mathrm{M}^{+}\right]$.

\subsection{Synthesis of 7-tert-butyl-1-(4-formylphenyl)-3-(4- $N, N$ - dimetylaminophenylethynyl)pyrene $(\boldsymbol{6} \boldsymbol{b})$}

A mix A mixture of 7-tert-butyl-1-(4-formylphenyl)-3bromopyrene $\mathbf{5 b}(120 \mathrm{mg}, 0.27 \mathrm{mmol}), \mathrm{N}, \mathrm{N}$-dimetylaminophenyl acetylene (78 mg, $0.54 \mathrm{mmol}), \mathrm{PPh}_{3}(6.7 \mathrm{mg}, 0.027 \mathrm{mmol}), \mathrm{CuI}$ (5 mg, $0.27 \mathrm{mmol}), \mathrm{PdCl}_{2}\left(\mathrm{PPh}_{3}\right)_{3}(10 \mathrm{mg}, 0.027 \mathrm{mmol})$ were added to a degassed solution of DMF $(6 \mathrm{~mL})$ and $\mathrm{Et}_{3} \mathrm{~N}(6 \mathrm{~mL})$. The resulting mixture was stirred at $100{ }^{\circ} \mathrm{C}$ for $24 \mathrm{~h}$. After it was cooled to room temperature, the reaction was quenched with water. The mixture was extracted with $\mathrm{CH}_{2} \mathrm{Cl}_{2}(2 \times 40 \mathrm{~mL})$, the organic layer was washed with water $(2 \times 30 \mathrm{~mL})$ and brine $(30$ $\mathrm{mL})$, and then the solution was dried $\left(\mathrm{MgSO}_{4}\right)$, and evaporated. The residue was purified by column chromatography eluting with a hexane- $\mathrm{CHCl}_{3}(1: 1)$ mixture to give $\mathbf{6} \mathbf{b}$ as an orange crystalline powder (53.5 mg, 39\%). M.p. $255-257{ }^{\circ} \mathrm{C}$; ${ }^{1} \mathrm{H}$ NMR $(400 \mathrm{MHz}$, $\left.\mathrm{CDCl}_{3}\right) \delta(\mathrm{ppm})=1.60(\mathrm{~s}, 9 \mathrm{H}, t \mathrm{Bu}), 3.04(\mathrm{~s}, 6 \mathrm{H}, \mathrm{NMe}), 6.74(\mathrm{~d}$, $J=7.5 \mathrm{~Hz}, 2 \mathrm{H}, \operatorname{Ar}-H), 7.60(\mathrm{~d}, J=8.9 \mathrm{~Hz}, 2 \mathrm{H}, \operatorname{Ar}-H), 7.83$ (d, $J$ $=7.8 \mathrm{~Hz}, 2 \mathrm{H}, \operatorname{Ar}-H), 8.03(\mathrm{~s}, 2 \mathrm{H}$, pyrene- $H), 8.07(\mathrm{~d}, J=7.8 \mathrm{~Hz}$, 
$2 \mathrm{H}, \operatorname{Ar}-H), 8.09$ (s, $1 \mathrm{H}$, pyrene- $H), 8.18(\mathrm{~d}, J=10.2 \mathrm{~Hz}, 1 \mathrm{H}$, pyrene- $H$ ), $8.22(\mathrm{~s}, 1 \mathrm{H}$, pyrene- $H), 8.29(\mathrm{~s}, 1 \mathrm{H}$, pyrene- $H), 8.69$ $(\mathrm{d}, J=10.0 \mathrm{~Hz}, 1 \mathrm{H}$, pyrene- $H), 10.16(\mathrm{~s}, 1 \mathrm{H}, \mathrm{CHO}) .{ }^{13} \mathrm{C} \mathrm{NMR}$

$\left(100 \mathrm{MHz}, \mathrm{CDCl}_{3}\right) \delta(\mathrm{ppm})=192.23,150.41,149.78,147.40$ $135.65,135.39,133.03,131.48,131.39,131.34,130.90,131.07$, $130.28,129.95,128.77,128.62,127.84,125.79,125.07,124.52$, $123.32,122.99,122.92,118.75,112.04,110.14,97.06,86.58$, $40.38,35.40,32.02$. FAB-MS: $m / z$ calcd for $\mathrm{C}_{37} \mathrm{H}_{31} \mathrm{NO} 505.2406$ $\left[\mathrm{M}^{+}\right]$; found $505.2357\left[\mathrm{M}^{+}\right]$.

\section{Acknowledgments}

This work was performed under the Cooperative Research Program of "Network Joint Research Center for Materials and Devices (Institute for Materials Chemistry and Engineering, Kyushu University)". We would like to thank the Natural Science Foundation of Shandong Province (Grant No. ZR2019BB067) The EPSRC is thanked for an overseas travel grant to C.R. (EP/R023816/1).

\section{Supplementary data}

Electronic Supplementary Information (ESI) available: Details of ${ }^{1} \mathrm{H},{ }^{13} \mathrm{C}$ NMR for compounds $\mathbf{4 ,} 5$ and $\mathbf{6}$; Photophysical properties of $\mathbf{6}$ and 7. For ESI and other electronic format see DOI: $10.1039 / \mathrm{x} 0 \mathrm{xx} 00000 \mathrm{x}$

\section{References and notes}

1. Figueira-Duarte, T. M.; Müllen K. Chem. Rev. 2011, 111, 7260-7314.

2. Feng, X.; Hu, J.-Y.; Redshaw, C.; Yamato, T. Chem. Eur. J. 2016, 22, 11898-11916.

3. Islam, M. M.; Hu, Z.; Wang, Q. S.; Redshaw, C.; Feng, X. Mater. Chem. Front. 2019, 23, 762-781.

4. Casas-Solvas, J. M.; Howgego, J. D.; Davis, A. P. Org. Biomol. Chem. 2014, 12, 212-232.

5. Levi, L.; Müller, T. J. J. Chem. Soc. Rev. 2016, 45, 2825-2846.

6. Merz, J.; Dietz, M.; Vonhausen, Y.; Wöber, F.; Friedrich, A.; Sieh, D.; Krummenacher, I.; Braunschweig, H.; Moos, M.; Holzapfel, M.; Lambert, C.; Marder, T. B. Chem. Eur. J. 2020, 26, 438-453.

7. Oh, J.-W.; Lee, Y. O.; Kim, T. H. Ko, K. C.; Lee, J. Y.; Kim, H.; Kim, J. S. Angew. Chem. Int. Ed. 2009, 48, 2522-2524.

8. Niko, Y.; Kawauchi, S.; Konishi, G-i. Chem. Eur. J. 2013, 19, 9760-9765.

9. Wu, Y.; Wang, J.; Zeng, F.; Huang, S.; Huang, J.; Xie, H.; Yu, C.; Wu, S. ACS Appl. Mater. Interfaces 2016, 8,1511-1519.

10. Zych, D. Molecules 2019, 24, 2551-2583.

11. Niko, Y.; Sasaki, S.; Narushima, K.; Sharma, D. K. Vacha, M.; Konishi, G.-I. J. Org. Chem. 2015, 80,10794-10805.

12. Feng, X.; Qi. C.; Feng, H.-T.; Zhao, Z.; Sung, H. H. Y.; Williams, L. D.; Kwok, R. T. K.; Lam, J. W. Y.; Qin, A.; Tang, B. Z. Chem. Sci. 2018, 9, 5679-5687.

13. Merz, J.; Fink, J.; Friedrich, A.; Krummenacher, I.; Al Mamari, H. H.; Lorenzen, S.; Haehnel, M.; Eichhorn, A.; Moos, M.; Holzapfel, M.; Braunschweig, H.; Lambert, C.; Steffen, A.; Ji, L.; Marder, T. B. Chem. Eur. J. 2017, 23, 13164-13180.

14. Ji, L.; Lorbach, A.; Edkins, R. M.; Marder, T. B. J. Org. Chem. 2015, 80, 5658-5665.

15. Crawford, A. G.; Dwyer, A.D.; Liu, Z.; Steffen, A.; Beeby, A.; Pålsson, L.-O.; Tozer, D. J.; Marder, T. B. J. Am. Chem. Soc. 2011, 133, 13349-13362.

16. Wang, C. Z.; Feng, X.; Kowser, Z.; Wu, C.; Akther, T.; Elsegood M. R. J.; Redshaw, C.; Yamato, T. Dyes Pigm. 2018, 153, 125131.

17. Zöphel, L.; Beckmann, D.; Enkelmann, V.; Chercka, D.; Rieger, R.; Müllen, K. Chem. Commun. 2011, 47, 6960-6962.

18. Zöphel, L.; Enkelmann, V.; Müllen, K. Org. Lett. 2013, 15, 804807.

19. Keller, S. N.; Veltri, N. L.; Sutherland, T. C. Org. Lett. 2013, 15, 4798-4801.
20. Keller, S. N.; Bromby, A. D. Sutherland, T. C. Eur. J. Org. Chem. 2017, 3980-3985.

21. Hogan, D. T.; Gelfand, B. S.; Spasyuk, D. M.; Sutherland, T. C. Mater. Chem. Front. 2020, 4, 268-276.

22. Zhang, R.; Zhao, Y.; Zhang, T.; Xu, L.; Ni, Z. Dyes Pigm. 2016, $130,106-115$.

23. Zhang, R.; Sun, H.; Zhao, Y.; Tang, X.; Ni, Z. Dyes Pigm. 2018,152, 1-13.

24. Wang, C. Z.; Ichiyanagi, H.; Sakaguchi, K.; Feng, X.; Elsegood, M. R. J.; Redshaw, C.; Yamato, T. J. Org. Chem. 2017, 82, 1767182 .

25. Figueira-Duarte, T. M.; Simon, S. C.; Wagner, M.; Druzhinin, S. I.; Zachariasse, K. A.; Mullen, K. Angew. Chem. Int. Ed. 2008, 47, 10175-10178

26. Feng, X.; Hu, J.-Y.; Yi, L.; Seto, N.; Tao, Z.; Redshaw, C.; Elsegood, M. R. J.; Yamato, T. Chem. Asian. J. 2012, 7, 28542863.

27. Feng, X.; Hu, J.-Y.; Tomiyasu, H.; Tao, Z.; Redshaw, C.; Elsegood, M. R. J.; Horsburgh, L.; Teat, S. J.; Wei, X. F.; Yamato, T. RSC Adv. 2015, 5, 8835-8848.

28. Wang, C. Z.; Do, J. H.; Akther, T.; Feng, X.; Matsumoto, T.; Tanaka, J.; Redshaw, C.; Yamato, T. J. Lumin. 2017, 188, 388393.

29. Lippert, V. E.; Naturforsch, Z. Phys. Sci. 1955, 10, 541-545.

30. Mataga, N.; Kaifu, Y.; Koizumi, M. Bull Chem. Soc. Jpn. 1956, $29,465-470$

31. Liu, R.; Ran, H.; Zhao, Z.; Yang, X.; Zhang, J.; Chen, L.; Sun, H.; Hu, J.-Y. ACS Omega. 2018, 3, 5866-5875.

32. Yan, Z. Q.; Yang, Z. Y.; Wang, H.; Li, A. W.; Wang, L. P.; Yang, H. Gao, B. R. Spectrochim Acta: Mol. Biomol. Spectr. 2011, 78, $1640-1645$.

33. Wang, C. Z.; Zhan, R.; Sakaguchi, K.; Feng, X.; Yu, X.; Elsegood, M. R. J.; Teat, S. J.; Redshaw, C.; Yamato, T. ChemPhotoChem. 2018, 2, 749-756.

34. Jérome, D.; Schulz, H. J. Advances in Physics. 2002, 51, 293-479.

35. Sasaki, S.; Drummen, G.; Konishi, G-i. J. Mater. Chem. C. 2016, 4, 2731-2743.

36. Sumi, K.; Niko, Y.; Tokumaru, K.; Konishi, G-I. Chem. Commun. 2013, 49, 3893-3895. 


\section{Short axially asymmetrically 1, 3-disubstituted pyrene-based color-tunable}

\section{emitters: Synthesis, characterization and optical properties}

Chuan-Zeng Wang ${ }^{a, b}, \mathrm{Zi}_{\text {-Jin Pang }}{ }^{a}$, Ze-Dong Yu ${ }^{a}$, Zhao-Xuan Zeng ${ }^{a}$, Wen-Xuan Zhao ${ }^{a}, \mathrm{Zi}$-Yan

$$
\text { Zhou }^{a}, * \text {, Carl Redshaw }{ }^{c} \text {, Takehiko Yamato }{ }^{b, *}
$$

A strategy to access a new class of D- $\pi$-A pyrene-based emitters has been established. The strategy is not only useful in the design of novel chromophores but it could also enable the preparation of high-efficiency opto-electronic materials.

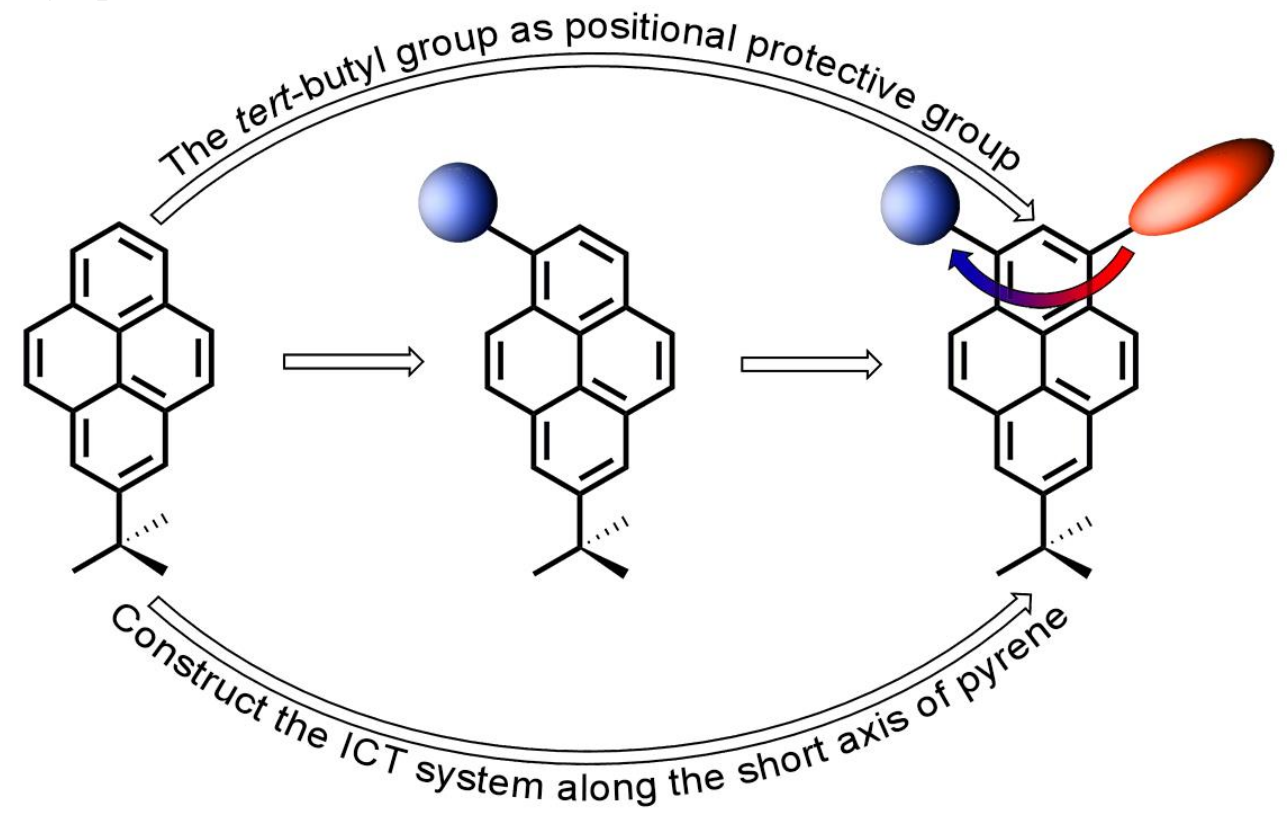


Highlights

- A new class of D- $\pi$-A pyrene-based emitters at 1,3-positions on pyrene ring was successfully designed and synthesized.

- Short axially asymmetrically 1-donor-3-acceptor pyrenes, two compounds exhibit efficient color-tunable properties

- Two compounds exhibit high thermal stability and good solubility. 
Click here to access/download Supplementary Material Supplementary Information.docx 
Dear Editor,

We are submitting the manuscript entitled "Short axially asymmetrically 1, 3-disubstituted pyrene-based color-tunable emitters: Synthesis, characterization and optical properties" for consideration as a full paper in Tetrahedron.

The authors declare no conflicts of interest associated with this manuscript.

Prof. Dr. Takehiko Yamato (corresponding author)

Department of Applied Chemistry

Faculty of Science and Engineering

Saga University

Honjo-machi 1, Saga-shi, Saga 840-8502, Japan

Fax: (internet.) + 81(0)952/28-8548

E-mail: yamatot@cc.saga-u.ac.jp 